Bio-grafía. Escritos sobre la Biología y su Enseñanza. ISSN 2027-1034

Número Extraordinario. p.p. 351-377

Memorias del Primer encuentro ambiental Universidad, ambiente y sustentabilidad: experiencias y prácticas.

\title{
UNA EXPERIENCIA DE SISTEMATIZACIÓN DEL I ENCUENTRO AMBIENTAL DE LA FACULTAD DE CIENCIA Y TECNOLOGÍA DE LA UNIVERSIDAD PEDAGÓGICA NACIONAL.
}

\begin{abstract}
SEMINARIO DE EDUCACIÓN AMBIENTAL. CICLO DE PROFUNDIZACIÓN. DEPARTAMENTO DE BIOLOGÍA.
\end{abstract}

\author{
Lina María Garcés Pico ${ }^{1}$ \\ Yedizareth Guerrero ${ }^{2}$ \\ Diana Paola Merchán ${ }^{3}$ \\ Viviana Andrea Monroy ${ }^{4}$ \\ José Luis Rincón ${ }^{5}$ \\ Sonia Martínez 6
}

La realización de este Primer encuentro ambiental Universidad, ambiente y sustentabilidad, permitió conocer las ideas, los discursos, actividades, talleres y proyectos, que se llevan a cabo en diferentes escenarios educativos, orientados por la Facultad de Ciencia y Tecnología, de la Universidad Pedagógica Nacional, como parte de las acciones del Eje cuatro del Plan de Desarrollo Institucional. PDI. 2014/2019; reconociendo la pertinencia e importancia de la dimensión ambiental en la educación superior.

Este encuentro ambiental, concibe las prácticas y los desarrollos en educación, enmarcados en la diversidad como creando espacios de construcción colectiva, en el que la educación Básica, Media y Universitaria fomentan y exaltan el trabajo realizado desde los diferentes contextos, culturas, políticas, y éticas, brindando herramientas para fortalecer los procesos de educación ambiental que promuevan cambios de actitud y transformación de prácticas culturales, y reglas de comportamiento en la comunidad educativa y la población en general, según los planteamientos y la sistematización de un grupo de estudiantes en formación registrados en el Seminario de Educación Ambiental en el

\footnotetext{
${ }^{1}$ Estudiante del Seminario de Educación ambiental. Departamento de Biología. Universidad pedagógica Nacional. dbi lgarces708@pedagogica.edu.co

${ }^{2}$ Estudiante del Seminario de Educación ambiental. Departamento de Biología. Universidad pedagógica Nacional.dbi_yguerrero165@pedagogica.edu.co.

. Estudiante del Seminario de Educación ambiental. Departamento de Biología.

Universidad pedagógica Nacional.dbi_dmerchan606@pedagogica.edu.co.

${ }^{4}$ Estudiante del Seminario de Educación ambiental. Departamento de Biología. Universidad pedagógica Nacional. dbi vamonroys@pedagogica.edu.co.

${ }^{5}$ Estudiante del Seminario de Educación ambiental. Departamento de Biología. Universidad pedagógica Nacional. dbi_jrincon042@pedagogica.edu.co.

${ }^{6}$ Docente del Seminario de Educación ambiental. Departamento de Biología. Universidad pedagógica Nacional.semartinez@pedagogica.edu.co.
} 
Número Extraordinario. p.p. 351-377

Memorias del Primer encuentro ambiental Universidad, ambiente y sustentabilidad: experiencias y prácticas.

eje de Profundización, del Departamento del Proyecto Curricular en Licenciatura en Biología.

Quienes asumen que la educación ambiental traspasa todas las áreas del conocimiento contrastando las interacciones con la naturaleza, con las personas y con el medio ambiente, de forma que se desarrolle una vida equilibrada y solidaria para todos.

Así mismo, la Universidad como ente educador tiene un rol fundamental en los procesos de educación ambiental, social y cultural que configuran la ideología de los sujetos y que logra provocar transformaciones en las estructuras sociales y en la conciencia ciudadana. Los cambios en los sistemas educativos, la participación de la comunidad y la responsabilidad social son fundamentales para estar preparados ante los nuevos desafíos ambientales. De esta forma, la Universidad Pedagógica Nacional tiene la responsabilidad de ser parte activa de ese cambio promoviendo el diálogo por medio de estos encuentros de saberes para que estos cambios puedan ser incluidos en la educación colombiana.

Los talleres, los pósteres y las múltiples socializaciones que se presentaron en este encuentro ambiental contaron con temáticas establecidas desde múltiples perspectivas, todas ellas legitimadas desde las comunidades educativas de manera crítica e interactiva con los participantes, de tal manera que se aprecia el ambiente sustentable desde diferentes visiones que van desde lo social, político, económico hasta lo científico, entendiendo así que este debe ser comprendido desde todos los ámbitos, y no se debe limitar únicamente a las ciencias.

A partir de lo anterior, se hará énfasis en caracterizar algunas muestras de trabajos representativos, el primero se llamaba "Bodyway: estereotipos de belleza en la escuela: incidencia de los medios y repercusión en los contextos" el cual fue desarrollado por el profesor Diego Rondón del Liceo Parroquial San José con ayuda de sus estudiantes de décimo grado, en donde se dividió el taller en tres partes, la primera consistía mostrar unas imágenes de representaciones virtuales, para que los asistentes pudieran escoger entre una persona que se acomoda a los estereotipos de belleza y otra persona del común y con base a ello se le daba un dinero (en papel) al asistente, según su elección (las personas del común tenían más valor que las estereotipadas), en la segunda parte del taller con el dinero que se obtuvo en la primera se escogen y compran láminas que representaban partes del cuerpo y globos (que representaban penes y senos) con los cuales se iban a elaborar los estereotipos de personas que se acomodaban a los gustos de los asistentes (esto se realizó por grupos) y en la última parte se realizó una retroalimentación del proceso y el por qué se escogieron tales caracterizaciones para la elaboración del tipo de personas y también sobre el consumismo e imaginarios de una sociedad 
Número Extraordinario. p.p. 351-377

Memorias del Primer encuentro ambiental Universidad, ambiente y sustentabilidad: experiencias y prácticas.

que estigmatiza las modas y acelera la exclusión social, y el desequilibrio ambiental.

Este taller encauza al ambiente en la medida que mencionaba que el seguir con un tipo de belleza determinado por la sociedad se consumían los recursos naturales de una manera desmesurada, pues el uso de textiles que son extraídos de fibras naturales se incrementa en pro de la moda y esto podría ocasionar malos manejos de los recursos, además de las fábricas de cosméticos que en ocasiones se valen de los animales para hacer pruebas con ellos, los cuales les pueden causar dolor y hasta la muerte.

Por otro lado el aspecto pedagógico se ve presente desde la importancia de tomar conciencia frente al tipo de conductas superficiales, ya que por prestar atención a las apariencias físicas se pasa por alto la importancia de conocer al ser en su esencia y la labor docente debe procurar hacer énfasis en la construcción de seres humanos que tengan en cuenta lo que los demás les pueden ofrecer desde lo que son como personas antes que enfatizar en lo que aparentan, así plantear un buen vivir desde la perspectiva de Sustentabilidad.

El segundo trabajo, en forma de taller se denominó "Impacto de los megaproyectos en la ciudad de Bogotá" el cual fue dirigido por un grupo de cuatro estudiantes, tres eran estudiantes de la Pedagógica de Licenciatura en Física y el otro era estudiante de la Universidad Nacional, el taller consistió en poner un mapa grande de la ciudad de Bogotá en el centro de los mesones del salón, en el cual empezaron a explicar el modelo de ciudad que se estaba empezando a pensar a través de los proyectos arquitectónicos o megaproyectos, que se tenían pensados a futuro, para exponer cada una de las implicaciones de cada proyecto se valieron de artículos de periódicos actuales, de manera virtual, para validar las propuestas de éstos proyectos, en y se colocaban y aglomeraban maquetas en miniatura sobre el mapa con escala de las edificaciones para mejor comprensión.

De este taller se puede evidenciar que su perspectiva medio ambiental se encuentra enfocada en lo socio-político, colocando en la mira algunas zonas sobre los cerros orientales, alterando el paisaje, y que no son estructuras propiamente naturales, ya que algunas de estas estructuras se pretenden levantar sobre humedales, lo cual impediría que la dinámica del ecosistema se lleve adecuadamente repercutiendo en la destrucción de fauna y flora y el desplazamiento de comunidades de bajos recursos, para construir centros financieros y empresariales.

Desde una visión más pedagógica, invita a los asistentes del taller a tomar una participación crítica, en la medida que invita a que se pronuncien en su participación ciudadana, debido a que son decisiones 
Número Extraordinario. p.p. 351-377

Memorias del Primer encuentro ambiental Universidad, ambiente y sustentabilidad: experiencias y prácticas.

que están tomando unos pocos que afectan a la sociedad empezando por el desplazamiento de la gente de sus propios terrenos para poder levantar las edificaciones y posteriormente elevando los costos de vida, lo cual ocasionará que sea cada vez más difícil vivir en la ciudad y así solamente tendrán acceso las personas con altos poderes adquisitivos.

Otro taller se titula "Prácticas de laboratorio sustentables: un diálogo desde el cuidado del ambiente y la enseñanza de la física. Una propuesta desde la máquina de Goldberg" eran cuatro talleres que se presentaban en simultánea, los cuatro exponían un prototipo de máquina desde diferentes áreas de la física como lo son la termodinámica, electromagnetismo, dinámica y cinemática, todas tenían en común que realizaban una función a partir de un efecto dominó de sus componentes.

A nivel ambiental, se pudo apreciar que se puede emplear energía limpia para poder ejecutar una tarea, en cómo la energía potencial se convierte en energía cinética, la cual era el impuso para poder llevar a cabo una acción final, de esta manera la obtención de energía no era invasiva para el ambiente ya que no generaba ningún daño sobre el mismo.

A nivel pedagógico se podría promover la creatividad de los asistentes, ya que se les daban materiales para la construcción de la máquina de Goldberg a partir de una explicación de su funcionamiento, y la idea era recrear de manera que fuera funcional, que varios asistentes la construyeron de diferentes maneras y ejecutaran satisfactoriamente el proceso de la máquina como tal.

Por lo anterior los trabajos, charlas, pósteres, talleres, expusieron la importancia de conservar el medio ambiente desde diferentes perspectivas, evidenciando la diversidad de pensamientos, donde los profesores cumplen un papel fundamental en procura de la promoción de más espacios como estos, poniendo al alcance de la comunidad educativa una reflexión de manera creativa para que se pueda generar una crítica, aquí los estudiantes en respuesta a este tipo de actividades generan una postura analítica, frente a lo que se les expone, haciendo que estos espacios sean enriquecedores en la medida que se da una retroalimentación.

La sustentabilidad se constituye en una fuente de pensamiento, de cultura, donde la educación ambiental responden a las diferentes características del buen vivir, se entreteje por unos enunciados básicos, dando sentido a la identidad, el territorio, el contexto, la caracterización de las comunidades; ya que tiene fundamentación ética y política, prácticas sociales arraigadas que giran en torno a la posibilidad de ser aprendidas y desarrolladas para pensar y resolver problemas educativos y sociales de contexto. 
Número Extraordinario. p.p. 351-377

Memorias del Primer encuentro ambiental Universidad, ambiente y sustentabilidad: experiencias y prácticas.

Este Encuentro ambiental fue fundamental para acceder al posicionamiento de las Instituciones Educativas como espacios donde se materializa la dimensión ambiental pertinente y de calidad para todos, a través de proyectos concretos, definidos y concertados por toda la comunidad que los maestros en formación y en ejercicio inicien y profundicen en términos de reflexión permanente sobre su quehacer en el aula, de todas las áreas, se desarrollan enfoques metodológicos de enseñanza flexibles, en relación pedagógica y uso de recursos para generar praxis pedagógica.

La reflexión debe incluir procesos fenomenológicos, estudios de casos, teniendo en cuenta componentes como corrientes pedagógicas, epistemologías, sustentables como elementos particulares de cada profesor, planeación en el aula como tarea para prever, anticipar, organizar y no para improvisar las actividades que se realiza con los estudiantes, y como proceso, ayuda al docente a descubrir hasta dónde llegaron, qué niveles de competencia alcanzaron y qué debilidades existieron en el proceso; en esa medida, se aprovecha las circunstancias a veces desfavorables, como oportunidad de aprendizaje, para descubrir amenazas y convertirlas en oportunidades, descubrir debilidades y convertirlas en fortalezas en las instituciones educativas, para lograr que los estudiantes en formación reflexionen, generen conocimiento y asuman las consecuencias sociales.

Y por último la dimensión ambiental hace parte de un proceso que busca el análisis frente a los procesos educativos actuales, donde pueda comprenderse cómo se encuentra la institución frente, el desempeño de docentes y el territorio, se definen acciones concretas para el mejoramiento, además se plantea la autoevaluación para generar un mayor alcance de los análisis que la educación ambiental busca para mejorar.

Con el objetivo de ampliar otras experiencias que se realizaron en el Primer encuentro, presentamos a continuación una matriz de sistematización propuesta y desarrollada en el marco del Seminario de profundización en Educación Ambiental, la cual además de presentar una foto representativa, posibilitó el ejercicio de identificación de presupuestos pedagógicos y ambientales de los diferentes trabajos. Esperamos que este material les permita dimensionar la apropiación ambiental que realizan personas y grupos de nuestra universidad y que además de disfrutarlo posibilite nuevas prácticas ambientales y sustentables por parte de cada uno de nosotros.

Del que se obtuvieron hallazgos como la diversidad y riqueza en las prácticas ambientales, desde las acciones de concientización hasta trabajos de psicología ambiental, su impacto en lo socio-político y de salud clínica, estos sentidos hacen 
Bio-grafía. Escritos sobre la Biología y su Enseñanza. ISSN 2027-1034

Número Extraordinario. p.p. 351-377

Memorias del Primer encuentro ambiental Universidad, ambiente y sustentabilidad: experiencias y prácticas.

que se enriquezcan las miradas hacia la dimensión ambiental de la FCT, como una evidencia más y no solo desde la teoría en clase.

Este material refleja el desarrollo de un grupo de estudiantes del Ciclo de Profundización del Seminario de Educación Ambiental, quienes realizaron el registro fotográfico del I Encuentro Ambiental de la Facultad de Ciencia y Tecnología de la UPN. 2016.2. 


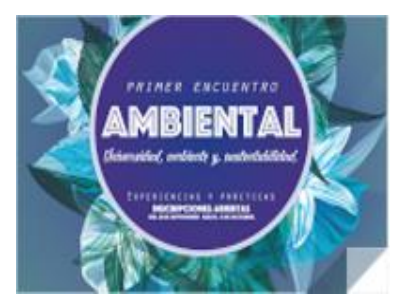

\section{UNIVERSIDAD PEDAGÓGICA NACIONAL}

\section{FACULTAD DE CIENCIA Y TECNOLOGÍA}

DEPARTAMENTO DE BIOLOGÍA

\section{SEMINARIO DE PROFUNDIZACION EN EDUCACION AMBIENTAL 2016.2}

\begin{tabular}{|c|c|c|c|c|c|c|c|}
\hline Foto & Descripción & Análisis & $\begin{array}{c}\text { Visión } \\
\text { pedagógica }\end{array}$ & Visión ambiental & $\begin{array}{c}\text { Autor de la } \\
\text { ponencia (taller, } \\
\text { poster, charla) }\end{array}$ & $\begin{array}{l}\text { Quien realizo el } \\
\text { registro }\end{array}$ & Observaciones \\
\hline 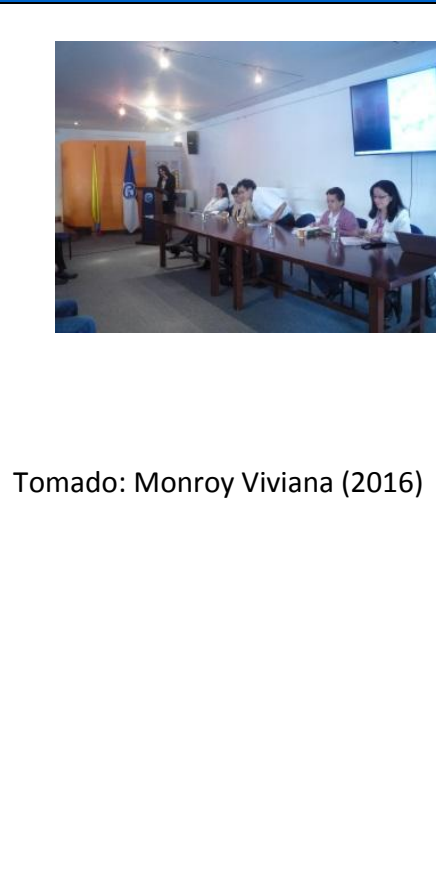 & $\begin{array}{l}\text { Grupos } \\
\text { investigador. }\end{array}$ & $\begin{array}{l}\text { El proyecto está } \\
\text { organizando un } \\
\text { evento de carácter } \\
\text { Reflexivo e } \\
\text { interpretativo que } \\
\text { nos permita } \\
\text { continuar la } \\
\text { discusión sobre la } \\
\text { educación } \\
\text { ambiental más } \\
\text { adecuadamente } \\
\text { para pensar las } \\
\text { relaciones entre } \\
\text { grupos de } \\
\text { Investigación y } \\
\text { estructura } \\
\text { ambiental de los } \\
\text { postgrados. }\end{array}$ & $\begin{array}{l}\text { La educación } \\
\text { Ambiental } \\
\text { muestra sus } \\
\text { visiones de } \\
\text { integración en la } \\
\text { Facultad de } \\
\text { Ciencia y } \\
\text { Tecnología de la } \\
\text { comunidad } \\
\text { Universitaria y así } \\
\text { intentar } \\
\text { comprender su } \\
\text { enseñanza dentro } \\
\text { del currículo. }\end{array}$ & $\begin{array}{l}\text { - El proyecto es la } \\
\text { imputabilidad de } \\
\text { una valoración } \\
\text { positiva o negativa } \\
\text { por el impacto } \\
\text { ecológico de una } \\
\text { decisión. } \\
\text { - Investigación en } \\
\text { epidemiología } \\
\text { ambiental. }\end{array}$ & $\begin{array}{l}\text { Panel de } \\
\text { apertura, } \\
\text { precedido por los } \\
\text { Directores de } \\
\text { Departamento y } \\
\text { Decano de la } \\
\text { Facultad de } \\
\text { Ciencia y } \\
\text { Tecnología } \\
\text { Profesores: } \\
\text { Norma Constanza } \\
\text { Castaño Cuellar } \\
\text { Directora } \\
\text { Departamento } \\
\text { de Biología } \\
\text { Lyda Constanza } \\
\text { Mora Mendieta } \\
\text { Directora } \\
\text { Departamento de } \\
\text { Matemáticas Rosa } \\
\text { Pedreros } \\
\text { Fidel Antonio } \\
\text { Cárdenas Salgado }\end{array}$ & $\begin{array}{l}\text { Los Autores } \\
\text { crean la } \\
\text { posibilidad de } \\
\text { este encuentro } \\
\text { ambiental en la } \\
\text { FCT de la UPN: } \\
\text {-Adriana Tovar } \\
\text {-Camilo Martínez } \\
\text {-Diana Moreno } \\
\text {-Diego Acero } \\
\text {-Julie Benavides } \\
\text { Melo } \\
\text {-Sandra Forero } \\
\text {-Sonia Martínez } \\
\text {-Rocío Pérez } \\
\text { (Coordinadora) }\end{array}$ & $\begin{array}{l}\text { Los grupos } \\
\text { investigadores } \\
\text { presentan una } \\
\text { reflexión sobre la } \\
\text { pedagogía y la } \\
\text { educación } \\
\text { ambiental. Los } \\
\text { estudiantes } \\
\text { participantes y } \\
\text { asistentes al evento } \\
\text { escuchan el Panel } \\
\text { de apertura. Para } \\
\text { entender las } \\
\text { diferentes posturas } \\
\text { de la educación } \\
\text { ambiental desde los } \\
\text { currículos tanto en } \\
\text { la escuela en } \\
\text { educación Básica y } \\
\text { Media y la } \\
\text { educación Superior. }\end{array}$ \\
\hline
\end{tabular}




\section{FACULTAD DE CIENCIA Y TECNOLOGÍA}

DEPARTAMENTO DE BIOLOGÍA

I ENCUENTRO AMBIENTAL FCT-UNIVERSIDAD, AMBIENTE Y SUSTENTABILIDAD

\section{SEMINARIO DE PROFUNDIZACION EN EDUCACION AMBIENTAL 2016.2}

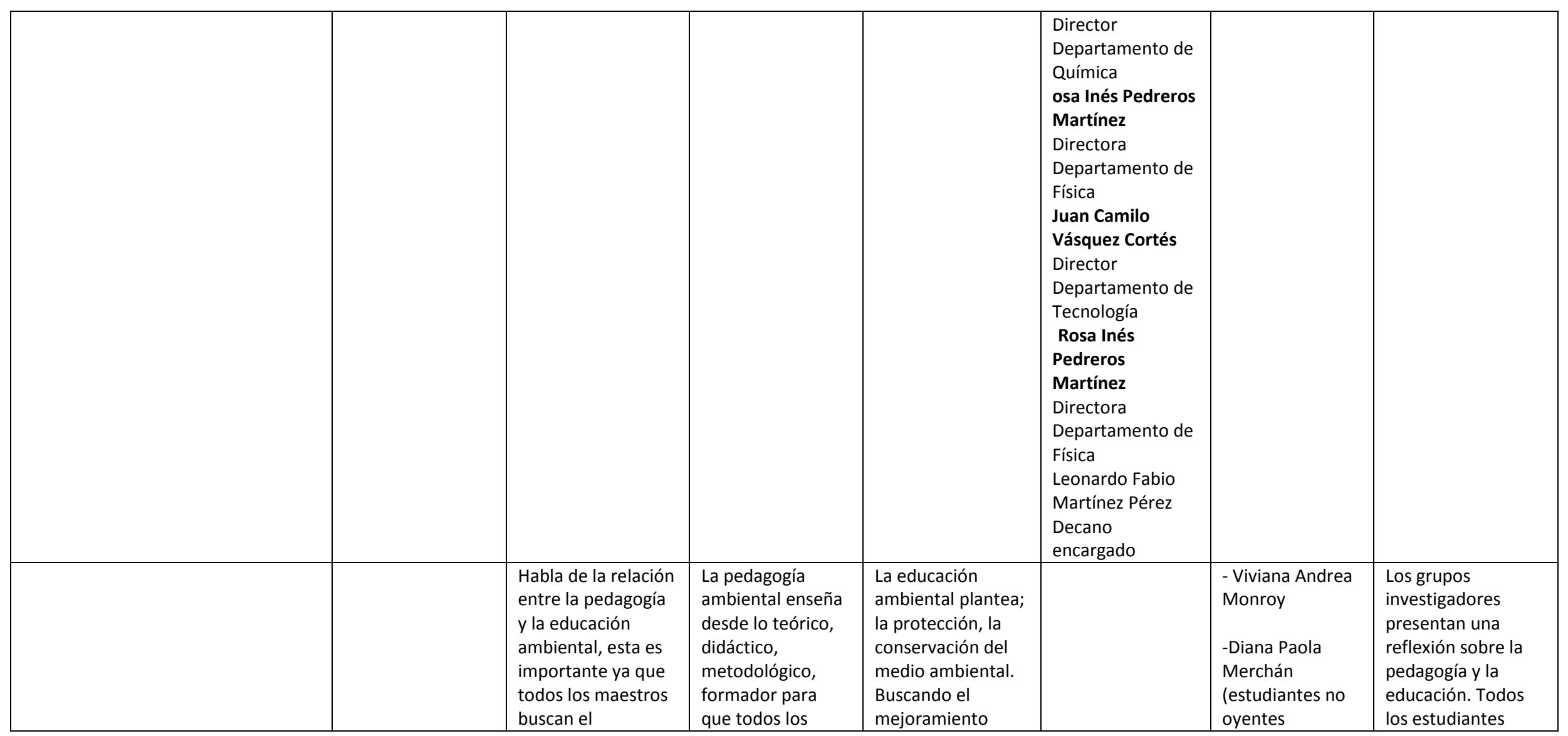




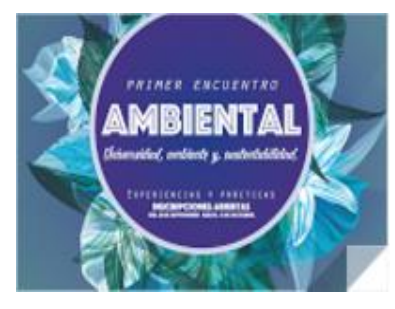

\section{UNIVERSIDAD PEDAGÓGICA NACIONAL}

\section{FACULTAD DE CIENCIA Y TECNOLOGÍA}

DEPARTAMENTO DE BIOLOGÍA

I ENCUENTRO AMBIENTAL FCT-UNIVERSIDAD, AMBIENTE Y SUSTENTABILIDAD

\section{SEMINARIO DE PROFUNDIZACION EN EDUCACION AMBIENTAL 2016.2}

\begin{tabular}{|c|c|c|c|c|c|c|c|}
\hline Tomado: Monroy Viviana (2016) & $\begin{array}{l}\text { Grupo } \\
\text { investigador. }\end{array}$ & $\begin{array}{l}\text { mejoramiento de la } \\
\text { calidad de vida y } \\
\text { también, los } \\
\text { estudiantes toman } \\
\text { una conciencia del } \\
\text { cuidado del } \\
\text { ambiente. }\end{array}$ & $\begin{array}{l}\text { estudiantes de } \\
\text { licenciatura de } \\
\text { biología, química, } \\
\text { física, diseño } \\
\text { tecnológico } \\
\text { podamos } \\
\text { aprender de esto } \\
\text { para que así } \\
\text { comprender a la } \\
\text { generalidad y la } \\
\text { interacción. }\end{array}$ & $\begin{array}{l}\text { medio ambiental y } \\
\text { la calidad en la } \\
\text { naturaleza. } \\
\text { También mejorar } \\
\text { en el futuro de las } \\
\text { especies que } \\
\text { habitan la Tierra }\end{array}$ & & $\begin{array}{l}\text { participaron en } \\
\text { la toma de } \\
\text { fotografías e } \\
\text { interpretación de } \\
\text { las mismas) }\end{array}$ & $\begin{array}{l}\text { están participando } \\
\text { de asistentes en } \\
\text { eventos. Para } \\
\text { ayuda a entender } \\
\text { mejor la pedagogía } \\
\text { y la educación. }\end{array}$ \\
\hline Tomado: Monroy Viviana (2016) & $\begin{array}{l}\text { El compromiso } \\
\text { ambiental de las } \\
\text { universidades en } \\
\text { Colombia: } \\
\text { Diagnóstico y } \\
\text { Perspectivas. }\end{array}$ & $\begin{array}{l}\text { El compromiso es } \\
\text { importante ya que } \\
\text { la protección del } \\
\text { medio ambiental es } \\
\text { principal para la } \\
\text { calidad de vida de } \\
\text { las generaciones y } \\
\text { futuro de } \\
\text { compromiso } \\
\text { ambiental en todas } \\
\text { las instituciones. }\end{array}$ & $\begin{array}{l}\text { Todos los } \\
\text { docentes deben } \\
\text { ser } \\
\text { comprometidos y } \\
\text { responsables con } \\
\text { la formación de } \\
\text { los estudiantes y } \\
\text { ciudadanía para } \\
\text { lograr mejorar las } \\
\text { prácticas } \\
\text { culturales } \\
\text { ambientales en } \\
\text { Colombia. }\end{array}$ & $\begin{array}{l}\text { La comunidad } \\
\text { universitaria } \\
\text { realiza y desarrolla } \\
\text { proyectos de } \\
\text { educación } \\
\text { ambiental, a través } \\
\text { de procesos } \\
\text { investigativos para } \\
\text { la educación en } \\
\text { Colombia. }\end{array}$ & $\begin{array}{l}\text { Autor: } \\
\text {-William Manuel } \\
\text { Mora Penagos } \\
\text { Conferencia }\end{array}$ & $\begin{array}{l}\text { - Viviana Andrea } \\
\text { Monroy } \\
\text {-Diana Paola } \\
\text { Merchán }\end{array}$ & $\begin{array}{l}\text { Plantea en su } \\
\text { conferencia la } \\
\text { investigación para } \\
\text { la inclusión de la } \\
\text { dimensión } \\
\text { ambiental en la } \\
\text { Universidad }\end{array}$ \\
\hline
\end{tabular}




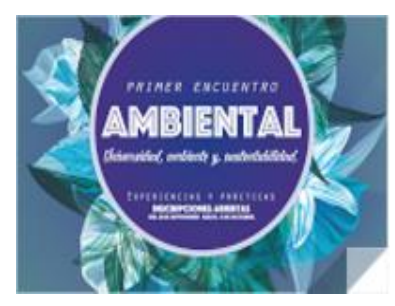

\section{FACULTAD DE CIENCIA Y TECNOLOGÍA}

DEPARTAMENTO DE BIOLOGÍA

I ENCUENTRO AMBIENTAL FCT-UNIVERSIDAD, AMBIENTE Y SUSTENTABILIDAD

\section{SEMINARIO DE PROFUNDIZACION EN EDUCACION AMBIENTAL 2016.2}

\begin{tabular}{|c|c|c|c|c|c|c|c|}
\hline Tomado: Monroy Viviana (2016) & $\begin{array}{l}\text { Los proyectos } \\
\text { ambientales } \\
\text { escolares (PRAE) } \\
\text { como experiencia } \\
\text { investigativa de } \\
\text { docentes en } \\
\text { formación inicial: } \\
\text { un aporte a la } \\
\text { promoción y } \\
\text { divulgación. }\end{array}$ & $\begin{array}{l}\text { Toma una reflexión } \\
\text { sobre el futuro en } \\
\text { el medio ambiental } \\
\text { y como todos los } \\
\text { maestros son } \\
\text { importantes } \\
\text { porque enseñan a } \\
\text { los diferentes tipos } \\
\text { de población. Los } \\
\text { maestros a su vez } \\
\text { aprenden. }\end{array}$ & $\begin{array}{l}\text { Los proyectos } \\
\text { escolares (PRAE) } \\
\text { son importantes } \\
\text { porque organizan } \\
\text { la formación para } \\
\text { la toma de } \\
\text { conciencia de los } \\
\text { problemas } \\
\text { ambientales, se } \\
\text { pueden remediar } \\
\text { esto enfocado en } \\
\text { fortalecimiento de } \\
\text { la conciencia } \\
\text { ambiental en la } \\
\text { sociedad civil. }\end{array}$ & $\begin{array}{l}\text { El medio ambiental } \\
\text { escolares (PRAE), } \\
\text { tiene el objeto de } \\
\text { fortalecer la } \\
\text { formación en } \\
\text { investigación de } \\
\text { docentes y } \\
\text { estudiantes en la } \\
\text { formación con el } \\
\text { objetivo de cuidar } \\
\text { la naturaleza. }\end{array}$ & $\begin{array}{l}\text { Autores: } \\
\text {-Leidy Yurani } \\
\text { Ordoñez } \\
\text {-Carlos Mario } \\
\text { Riveros } \\
\text {-María Velasco } \\
\\
\text { En edificio A y } \\
\text { piso } 2\end{array}$ & $\begin{array}{l}\text { - Viviana Andrea } \\
\text { Monroy } \\
\text {-Diana Paola } \\
\text { Merchán }\end{array}$ & $\begin{array}{l}\text { En la observación } \\
\text { de eventos sobre } \\
\text { los proyectos } \\
\text { ambientales } \\
\text { escolares (PRAE) } \\
\text { para que los } \\
\text { estudiantes } \\
\text { conozcan algunos } \\
\text { movimientos } \\
\text { ambientales en } \\
\text { Colombia. }\end{array}$ \\
\hline Tomado: Monroy Viviana (2016) & $\begin{array}{l}\text { Construcción de } \\
\text { celdas solares } \\
\text { como estrategia } \\
\text { metodológica } \\
\text { para mitigar los } \\
\text { problemas } \\
\text { ambientales } \\
\text { asociados al } \\
\text { consumo } \\
\text { energético } \\
\text { insostenible. }\end{array}$ & $\begin{array}{l}\text { Se busca mostrar } \\
\text { que el ambiente } \\
\text { está mal por la } \\
\text { contaminación de } \\
\text { agua, producción } \\
\text { de bonos de carbón } \\
\text { y transporte, por el } \\
\text { afán del desarrollo } \\
\text { económico. El } \\
\text { objetivo es ayudar } \\
\text { en una solución } \\
\text { ecológica. }\end{array}$ & $\begin{array}{l}\text { La presentación } \\
\text { muestra } \\
\text { innovación de los } \\
\text { maestros } \\
\text { buscando la } \\
\text { estrategia } \\
\text { metodológica para } \\
\text { construir } \\
\text { conocimiento } \\
\text { para educar, } \\
\text { desde la } \\
\text { construcción de } \\
\text { paneles solares. }\end{array}$ & $\begin{array}{l}\text { La presentación de } \\
\text { trabajo muestra el } \\
\text { desequilibrio } \\
\text { ecológico por el } \\
\text { consumo de } \\
\text { energía } \\
\text { insostenible. } \\
\text { Buscan el } \\
\text { mejoramiento } \\
\text { cuidado de la } \\
\text { ecología con el uso } \\
\text { de la celda solar. }\end{array}$ & $\begin{array}{l}\text { Autoras: } \\
\text { propuestas desde } \\
\text { la Lic. Química } \\
\text {-Katherine López } \\
\text { Fernández } \\
\text {-Kimberly T. } \\
\text { Simbaqueva } \\
\text { Baquero } \\
\text { Poster: Edificio B } \\
\text { y Piso } 3\end{array}$ & $\begin{array}{l}\text { - Viviana Andrea } \\
\text { Monroy } \\
\text {-Diana Paola } \\
\text { Merchán }\end{array}$ & $\begin{array}{l}\text { En la observación: } \\
\text { sobre la estrategia } \\
\text { metodológica para } \\
\text { las celdas solares } \\
\text { para el } \\
\text { aprovechamiento } \\
\text { de la energía } \\
\text { limpia. }\end{array}$ \\
\hline
\end{tabular}




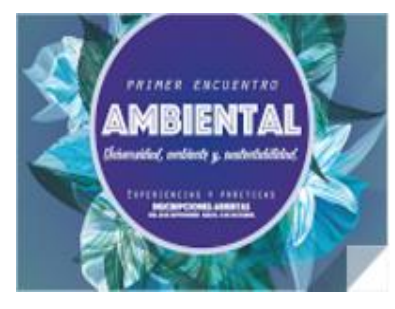

\section{UNIVERSIDAD PEDAGÓGICA NACIONAL}

FACULTAD DE CIENCIA Y TECNOLOGÍA

DEPARTAMENTO DE BIOLOGÍA

I ENCUENTRO AMBIENTAL FCT-UNIVERSIDAD, AMBIENTE Y SUSTENTABILIDAD

\section{SEMINARIO DE PROFUNDIZACION EN EDUCACION AMBIENTAL 2016.2}

\begin{tabular}{|c|c|c|c|c|c|c|c|}
\hline Tomado: Monroy Viviana (2016) & $\begin{array}{l}\text { Dermatofitosis } \\
\text { una enfermedad } \\
\text { dermatológica } \\
\text { que afecta a la } \\
\text { Ciénaga de la } \\
\text { Virgen. }\end{array}$ & $\begin{array}{l}\text { Se muestra el } \\
\text { proyecto que la } \\
\text { dermatofitosis es } \\
\text { producir un hongo } \\
\text { en piel de cabello y } \\
\text { las unas. Por lo } \\
\text { tanto, la } \\
\text { investigación } \\
\text { ayuda al } \\
\text { conocimiento de } \\
\text { los antioxidantes } \\
\text { para las personas } \\
\text { sanen y cuiden de } \\
\text { su piel. }\end{array}$ & $\begin{array}{l}\text { No es solo } \\
\text { medicina un saber } \\
\text { para todos, sino el } \\
\text { maestro biología y } \\
\text { química sabe la } \\
\text { enfermedad de } \\
\text { dermatofitosis es } \\
\text { el hongo, mientras } \\
\text { la relación entre } \\
\text { estudiantes y } \\
\text { maestro } \\
\text { comparten en la } \\
\text { clase para que los } \\
\text { estudiantes } \\
\text { conozcan la } \\
\text { enfermedad de } \\
\text { dermatofitosis. }\end{array}$ & $\begin{array}{l}\text { Se afecta a las } \\
\text { personas están } \\
\text { enfermedad de } \\
\text { dermatofitosis } \\
\text { porque el } \\
\text { ambiente está } \\
\text { sucio, por lo tanto, } \\
\text { la necesidad } \\
\text { cuidado al medio } \\
\text { ambiental en } \\
\text { Colombia, para } \\
\text { que no afecta a la } \\
\text { demás }\end{array}$ & $\begin{array}{l}\text { Autores: } \\
\text { Lic. Química } \\
\text {-Y. Méndez } \\
\text {-F. Suesca } \\
\text {-D. Rayo } \\
\text { Poster: Edificio B } \\
\text { y Piso } 3\end{array}$ & $\begin{array}{l}\text { - Viviana Andrea } \\
\text { Monroy } \\
\text { Sandoval } \\
\text {-Diana Paola } \\
\text { Merchán }\end{array}$ & $\begin{array}{l}\text { Los dos estudiantes } \\
\text { se ponen de } \\
\text { acuerdo con el } \\
\text { cuidado de la } \\
\text { virginidad. }\end{array}$ \\
\hline Tomado: Monroy Viviana (2016) & $\begin{array}{l}\text { Colombia Sin } \\
\text { Asbesto (Medio } \\
\text { Ambiente). }\end{array}$ & $\begin{array}{l}\text { Se analiza que en el } \\
\text { barrio Pablo } \\
\text { Neruda del pueblo } \\
\text { de Sibaté, las } \\
\text { personas no tienen } \\
\text { conocimiento sobre } \\
\text { cómo manejar los } \\
\text { residuos de la } \\
\text { fábrica Eternit, esto } \\
\text { es grave porque } \\
\text { afecta por la salud. }\end{array}$ & $\begin{array}{l}\text { Los maestros } \\
\text { tienen la } \\
\text { responsabilidad } \\
\text { de orientar a sus } \\
\text { habitantes sobre } \\
\text { la enseñanza y } \\
\text { cuidado por la } \\
\text { salud. }\end{array}$ & $\begin{array}{l}\text { En el ambiente se } \\
\text { afecta a las } \\
\text { personas, ellas } \\
\text { están mal de su } \\
\text { salud, debido al, } \\
\text { uso del mineral en } \\
\text { la industria. }\end{array}$ & $\begin{array}{l}\text { Autores: } \\
\text { Lic. Química } \\
\text {-Cesar Gutiérrez } \\
\text {-Camila Corredor } \\
\text {-Ángela Zea } \\
\text {-Julie Benavides } \\
\text { Poster: Edificio B } \\
\text { y Piso } 3\end{array}$ & $\begin{array}{l}\text { - Viviana Andrea } \\
\text { Monroy } \\
\text { Sandoval } \\
\text {-Diana Paola } \\
\text { Merchán }\end{array}$ & $\begin{array}{l}\text { La estudiante } \\
\text { explica que es } \\
\text { importante conocer } \\
\text { bien el medio } \\
\text { ambiente para ver } \\
\text { la problemática de } \\
\text { la salud en los seres } \\
\text { humanos } \\
\text { colombianos. }\end{array}$ \\
\hline & Propuesta & Se busca analizar la & El maestro es & Su propuesta de la & Autora: & & En la observación \\
\hline
\end{tabular}




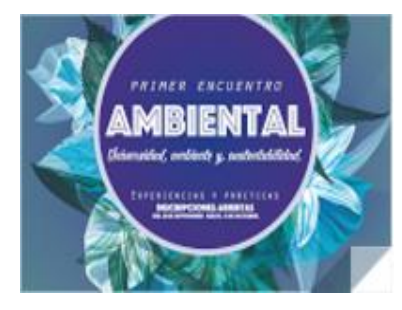

\section{FACULTAD DE CIENCIA Y TECNOLOGÍA}

DEPARTAMENTO DE BIOLOGÍA

I ENCUENTRO AMBIENTAL FCT-UNIVERSIDAD, AMBIENTE Y SUSTENTABILIDAD

\section{SEMINARIO DE PROFUNDIZACION EN EDUCACION AMBIENTAL 2016.2}

\begin{tabular}{|c|c|c|c|c|c|c|c|}
\hline Tomado: Monroy Viviana (2016) & $\begin{array}{l}\text { curricular para la } \\
\text { formación de } \\
\text { competencias } \\
\text { para el desarrollo } \\
\text { sostenible en el } \\
\text { programa de } \\
\text { salud } \\
\text { ocupacional. }\end{array}$ & $\begin{array}{l}\text { reflexión sobre la } \\
\text { formación para el } \\
\text { desarrollo } \\
\text { sostenible de la } \\
\text { educación } \\
\text { ambiental. }\end{array}$ & $\begin{array}{l}\text { importante en las } \\
\text { instituciones de } \\
\text { educación, enseña } \\
\text { al estudiante, que } \\
\text { el tema de } \\
\text { desarrollo } \\
\text { sostenible es } \\
\text { crítico y, que debe } \\
\text { desarrollar } \\
\text { habilidades y } \\
\text { valores para el } \\
\text { estudiante tenga } \\
\text { una posición } \\
\text { activa frente el } \\
\text { conocimiento. }\end{array}$ & $\begin{array}{l}\text { educación para el } \\
\text { desarrollo } \\
\text { sostenible surge de } \\
\text { la necesidad de la } \\
\text { poca participación } \\
\text { de las } \\
\text { universidades para } \\
\text { desarrollar este } \\
\text { tema, para todos } \\
\text { los profesionales } \\
\text { formados con una } \\
\text { visión y el } \\
\text { conocimiento } \\
\text { sobre entornos. }\end{array}$ & $\begin{array}{l}\text { Lic. Química } \\
\text {-Yolanda Ladino } \\
\text { Ospina. } \\
\text { Poster: Edificio B } \\
\text { y Piso } 3\end{array}$ & $\begin{array}{l}\text { - Viviana Andrea } \\
\text { Monroy } \\
\text { Sandoval } \\
\text {-Diana Paola } \\
\text { Merchán }\end{array}$ & $\begin{array}{l}\text { del evento sobre la } \\
\text { importancia de } \\
\text { educar para el } \\
\text { desarrollo } \\
\text { sostenible y todos } \\
\text { los estudiantes } \\
\text { aprenden el tema } \\
\text { es importante } \\
\text { porque atiende la } \\
\text { perspectiva } \\
\text { ambiental. }\end{array}$ \\
\hline Tomado: Monroy Viviana (2016) & $\begin{array}{l}\text { La educación } \\
\text { ambiental y las } \\
\text { comunidades de } \\
\text { aprendizaje en la } \\
\text { conformación de } \\
\text { redes juveniles en } \\
\text { la escuela. }\end{array}$ & $\begin{array}{l}\text { Se realiza en el } \\
\text { departamento del } \\
\text { Meta. Las } \\
\text { comunidades de } \\
\text { jóvenes, proponen } \\
\text { redes ambientales } \\
\text { sobre el impacto de } \\
\text { ambiental. }\end{array}$ & $\begin{array}{l}\text { En el } \\
\text { departamento del } \\
\text { Meta (Colombia), } \\
\text { su objetivo de } \\
\text { trabajo es el } \\
\text { medio ambiente y } \\
\text { toda la } \\
\text { participación de } \\
\text { jóvenes en la } \\
\text { construcción de } \\
\text { propuestas para } \\
\text { soluciones de } \\
\text { impacto local, } \\
\text { departamental y } \\
\text { nacional. }\end{array}$ & $\begin{array}{l}\text { Este es el trabajo } \\
\text { de investigación } \\
\text { tiene como } \\
\text { objetivo organizar } \\
\text { el ambiente y la } \\
\text { comunidad } \\
\text { educativa, } \\
\text { destacando su } \\
\text { responsabilidad } \\
\text { ambiental, su } \\
\text { reflexión y su } \\
\text { asertividad en la } \\
\text { toma de } \\
\text { decisiones. }\end{array}$ & $\begin{array}{l}\text { Autores: } \\
\text { Lic. Química } \\
\text {-Yolanda Ladino } \\
\text {-Andrés Felipe } \\
\text { Méndez } \\
\text { Poster: Edificio B } \\
\text { y Piso } 3\end{array}$ & $\begin{array}{l}\text { - Viviana Andrea } \\
\text { Monroy } \\
\text {-Diana Paola } \\
\text { Merchán }\end{array}$ & $\begin{array}{l}\text { En la observación } \\
\text { de eventos para las } \\
\text { comunidades de } \\
\text { aprendizaje sobre } \\
\text { el cuidado } \\
\text { ambiental orden } \\
\text { socio- ambiental. }\end{array}$ \\
\hline
\end{tabular}




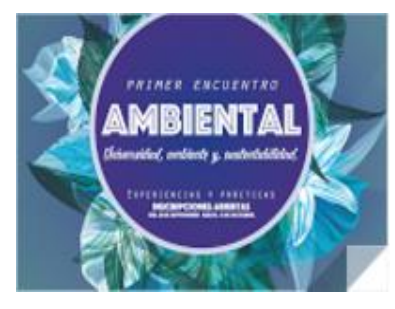

\section{UNIVERSIDAD PEDAGÓGICA NACIONAL}

FACULTAD DE CIENCIA Y TECNOLOGÍA

DEPARTAMENTO DE BIOLOGÍA

I ENCUENTRO AMBIENTAL FCT-UNIVERSIDAD, AMBIENTE Y SUSTENTABILIDAD

\section{SEMINARIO DE PROFUNDIZACION EN EDUCACION AMBIENTAL 2016.2}

\begin{tabular}{|c|c|c|c|c|c|c|c|}
\hline Tomado: Monroy Viviana (2016) & $\begin{array}{l}\text { La incidencia del } \\
\text { cambio climático } \\
\text { en las mariposas y } \\
\text { su relación con la } \\
\text { educación } \\
\text { ambiental en la } \\
\text { práctica } \\
\text { pedagógica. }\end{array}$ & $\begin{array}{l}\text { Se busca analizar la } \\
\text { práctica pedagógica } \\
\text { no formal en la } \\
\text { enseñanza } \\
\text { ambiental y la } \\
\text { educación para } \\
\text { aprender sobre la } \\
\text { conservación de } \\
\text { algunos grupos } \\
\text { Lepidóptera. }\end{array}$ & $\begin{array}{l}\text { Es importante la } \\
\text { práctica } \\
\text { pedagógica; se } \\
\text { busca la } \\
\text { formación a la } \\
\text { educación para } \\
\text { comprender la } \\
\text { conservación de } \\
\text { los grupos } \\
\text { Lepidóptera. Y la } \\
\text { enseñanza } \\
\text { ambiental en la } \\
\text { escuela para el } \\
\text { cuidado la } \\
\text { naturaleza. }\end{array}$ & $\begin{array}{l}\text { Los organismos } \\
\text { como las } \\
\text { mariposas son } \\
\text { importantes en la } \\
\text { escuela, para la } \\
\text { comprensión de la } \\
\text { biología, la } \\
\text { biodiversidad, la } \\
\text { educación } \\
\text { ambiental y la } \\
\text { conservación. Es } \\
\text { posible educar } \\
\text { entendiendo la } \\
\text { complejidad de la } \\
\text { Biología. }\end{array}$ & $\begin{array}{l}\text { Autores: } \\
\text { Lic. Biología } \\
\text { - Cristian López } \\
\text { - Víctor } \\
\text { Marulanda } \\
\text { Poster: Edificio B } \\
\text { y Piso } 3\end{array}$ & $\begin{array}{l}\text { - Viviana Andrea } \\
\text { Monroy } \\
\text {-Diana Paola } \\
\text { Merchán }\end{array}$ & $\begin{array}{l}\text { En la observación } \\
\text { del evento, su } \\
\text { objetivo es la } \\
\text { relación ambiental } \\
\text { y las mariposas } \\
\text { para entender y } \\
\text { comprender el } \\
\text { medio ambiente. }\end{array}$ \\
\hline Tomado: Monroy Viviana (2016) & $\begin{array}{l}\text { Colombia Sin } \\
\text { Asbesto } \\
\text { (Legislación). }\end{array}$ & $\begin{array}{l}\text { Se busca analizar } \\
\text { sobre el estudio de } \\
\text { ley de la } \\
\text { prohibición del uso } \\
\text { asbesto. Y la falta } \\
\text { de cumplimiento de } \\
\text { leyes respecto del } \\
\text { asbesto. }\end{array}$ & $\begin{array}{l}\text { Los grupos de } \\
\text { investigación se } \\
\text { proponen trabajar } \\
\text { sobre el proyecto } \\
\text { de ley que prohíbe } \\
\text { el uso del } \\
\text { peligroso mineral } \\
\text { de asbesto. }\end{array}$ & $\begin{array}{l}\text { Sabemos que es un } \\
\text { peligroso mineral } \\
\text { porque se afecta la } \\
\text { salud, por lo tanto, } \\
\text { todas las personas } \\
\text { en ámbitos } \\
\text { económicos, } \\
\text { políticos e } \\
\text { industriales. Deben } \\
\text { cuidar la salud y la } \\
\text { vida, además la } \\
\text { conservación de la } \\
\text { naturaleza en } \\
\text { Colombia. }\end{array}$ & $\begin{array}{l}\text { Autores: } \\
\text { Lic. Biología } \\
\text {-Cristian } \\
\text { Hernando Rivera } \\
\text { - Wilmar David } \\
\text { Díaz } \\
\text { - Julie Gesselle } \\
\text { Benavides } \\
\\
\text { Poster: Edificio B } \\
\text { y Piso } 3\end{array}$ & $\begin{array}{l}\text { - Viviana Andrea } \\
\text { Monroy } \\
\text {-Diana Paola } \\
\text { Merchán }\end{array}$ & $\begin{array}{l}\text { En la observación } \\
\text { de eventos trata } \\
\text { sobre el mineral de } \\
\text { amianto, tan } \\
\text { peligroso, para la } \\
\text { salud. Este es un } \\
\text { tema interesante. }\end{array}$ \\
\hline
\end{tabular}




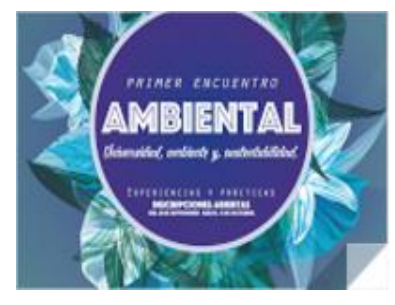

\section{UNIVERSIDAD PEDAGÓGICA NACIONAL}

FACULTAD DE CIENCIA Y TECNOLOGÍA

DEPARTAMENTO DE BIOLOGÍA

I ENCUENTRO AMBIENTAL FCT-UNIVERSIDAD, AMBIENTE Y SUSTENTABILIDAD

\section{SEMINARIO DE PROFUNDIZACION EN EDUCACION AMBIENTAL 2016.2}

\begin{tabular}{|c|c|c|c|c|c|c|c|}
\hline Tomado: Monroy Viviana (2 & $\begin{array}{l}\text { Estrategia } \\
\text { didáctica para la } \\
\text { valoración de los } \\
\text { tiburones con } \\
\text { estudiantes de la } \\
\text { IELLM del } \\
\text { municipio de } \\
\text { Bahía Solano } \\
\text { (Chocó). }\end{array}$ & $\begin{array}{l}\text { Se realizó un } \\
\text { análisis en el } \\
\text { municipio de Bahía } \\
\text { Solano del } \\
\text { departamento de } \\
\text { Chocó, su objetivo } \\
\text { el cuidado de los } \\
\text { tiburones por la } \\
\text { extinción. Para la } \\
\text { enseñanza de la } \\
\text { biodiversidad en } \\
\text { Bahía Solano - } \\
\text { Colombia. }\end{array}$ & $\begin{array}{l}\text { El trabajo de } \\
\text { investigación trata } \\
\text { la biología de la } \\
\text { conservación y el } \\
\text { objetivo realizar } \\
\text { una estrategia } \\
\text { didáctica para la } \\
\text { educación, una } \\
\text { actividad de los } \\
\text { estudiantes del } \\
\text { grado } 11 \text { de } \\
\text { bachillerato de la } \\
\text { Institución } \\
\text { Educativa Luis } \\
\text { López de Mesa. }\end{array}$ & $\begin{array}{l}\text { La presentación de } \\
\text { trabajo sobre } \\
\text { didáctica, que los } \\
\text { maestros piensan } \\
\text { ¿qué enseñar? } \\
\text { ¿Cómo enseñar? } \\
\text { ¿Por qué enseñar? } \\
\text { Para que los } \\
\text { estudiantes } \\
\text { conozcan las } \\
\text { especies de los } \\
\text { tiburones son } \\
\text { importantes } \\
\text { porque la vida en } \\
\text { el ambiente } \\
\text { marino. }\end{array}$ & $\begin{array}{l}\text { Autores: } \\
\text { Lic. Biología } \\
\text { - Juan Diego } \\
\text { Hidalgo. } \\
\text { - Hugo Javier } \\
\text { Loaiza. } \\
\text { Poster: Edificio B } \\
\text { y Piso } 3\end{array}$ & $\begin{array}{l}\text { - Viviana Andrea } \\
\text { Monroy } \\
\text {-Diana Paola } \\
\text { Merchán }\end{array}$ & $\begin{array}{l}\text { En la observación } \\
\text { de eventos sobre la } \\
\text { valoración de los } \\
\text { tiburones con } \\
\text { estudiante. Este } \\
\text { tema es pertinente, } \\
\text { de contexto e } \\
\text { importante para } \\
\text { estudiantes de } \\
\text { Bahía Solano en el } \\
\text { colegio Luis López } \\
\text { de Mesa. }\end{array}$ \\
\hline $\begin{array}{l}\text { Tomada por: Guerrero Yedizareth } \\
\text { (2016). }\end{array}$ & $\begin{array}{l}\text { Título: Bodyway: } \\
\text { estereotipos de } \\
\text { belleza en la } \\
\text { escuela, } \\
\text { incidencia de los } \\
\text { medios y } \\
\text { repercusión en los } \\
\text { contextos. } \\
\text { Taller realizado } \\
\text { por estudiantes } \\
\text { de décimo grado } \\
\text { del } \\
\text { Parroquial San } \\
\text { José, Siceo }\end{array}$ & $\begin{array}{l}\text { Se hace una } \\
\text { reflexión frente a la } \\
\text { manera en cómo se } \\
\text { entiende la belleza } \\
\text { exterior y a veces } \\
\text { tendemos a } \\
\text { dejarnos llevar por } \\
\text { el aspecto de las } \\
\text { personas y la moda } \\
\text { y no tanto por su } \\
\text { interior, ni sus } \\
\text { convicciones. }\end{array}$ & $\begin{array}{l}\text { Promover en los } \\
\text { estudiantes una } \\
\text { reflexión frente a } \\
\text { la manera en } \\
\text { cómo se perciben } \\
\text { en el medio en } \\
\text { que re } \\
\text { encuentran, e } \\
\text { identificar la } \\
\text { manera en que los } \\
\text { medios de } \\
\begin{array}{l}\text { comunicación } \\
\text { influyen en la } \\
\text { formación de los }\end{array}\end{array}$ & $\begin{array}{l}\text { El medio ambiente } \\
\text { se ve afectado en } \\
\text { la medida que se } \\
\text { hace uso de los } \\
\text { recursos naturales } \\
\text { para cumplir con } \\
\text { las expectativas de } \\
\text { belleza, es decir, } \\
\text { para la creación de } \\
\text { productos } \\
\text { cosméticos y ropa } \\
\text { a la moda. Lo cual } \\
\text { fortalece el } \\
\text { consumismo, }\end{array}$ & $\begin{array}{l}\text { Autor: } \\
\text { Taller } \\
\text { Diego Rondón } \\
\text { Profesor de } \\
\text { química del Liceo } \\
\text { Parroquial, con } \\
\text { ayuda de sus } \\
\text { estudiantes de } \\
\text { décimo grado. }\end{array}$ & $\begin{array}{l}\text { - Yedizareth } \\
\text { Guerrero } \\
\text { Cuadros }\end{array}$ & $\begin{array}{l}\text { Este tipo de } \\
\text { presentación al ser } \\
\text { de carácter } \\
\text { interactivo permitió } \\
\text { la participación de } \\
\text { los asistentes, lo } \\
\text { cual ayuda a que se } \\
\text { dé un acercamiento } \\
\text { a lo que se quiere } \\
\text { exponer, ayudando } \\
\text { a entender mejor la } \\
\text { idea de lo que se } \\
\text { quiere expresar. }\end{array}$ \\
\hline
\end{tabular}




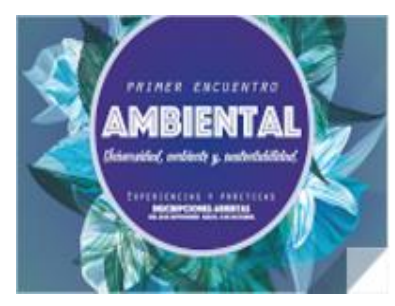

\section{UNIVERSIDAD PEDAGÓGICA NACIONAL}

\section{FACULTAD DE CIENCIA Y TECNOLOGÍA}

DEPARTAMENTO DE BIOLOGÍA

I ENCUENTRO AMBIENTAL FCT-UNIVERSIDAD, AMBIENTE Y SUSTENTABILIDAD

\section{SEMINARIO DE PROFUNDIZACION EN EDUCACION AMBIENTAL 2016.2}

\begin{tabular}{|c|c|c|c|c|c|c|c|}
\hline & $\begin{array}{lr}\text { evidenciar } & \text { la } \\
\text { manera en } & \text { que } \\
\text { afectan } & \text { los } \\
\text { estereotipos de } \\
\text { belleza a la } \\
\text { sociedad actual }\end{array}$ & & sujetos. & $\begin{array}{l}\text { deteriorando el } \\
\text { medio ambiente y } \\
\text { la cultura. }\end{array}$ & & & \\
\hline $\begin{array}{l}\text { Tomada por: Guerrero Yedizareth } \\
\text { (2016). }\end{array}$ & $\begin{array}{l}\text { Título: Impacto de } \\
\text { los mega } \\
\text { proyectos en la } \\
\text { ciudad de Bogotá. }\end{array}$ & $\begin{array}{l}\text { Se expone en qué } \\
\text { consisten } \\
\text { diferentes } \\
\text { proyectos de } \\
\text { nuevas } \\
\text { infraestructuras } \\
\text { para la ciudad de } \\
\text { Bogotá, } \\
\text { principalmente en } \\
\text { el centro de la } \\
\text { ciudad. }\end{array}$ & $\begin{array}{l}\text { Cada estructura } \\
\text { que se pretende } \\
\text { levantar en la } \\
\text { capital tiene una } \\
\text { intención } \\
\text { económica detrás } \\
\text { de ésta, que solo } \\
\text { beneficia a } \\
\text { algunos pocos, } \\
\text { enfáticamente a } \\
\text { las personas que } \\
\text { pertenecen al } \\
\text { sector privado } \\
\text { financiero. }\end{array}$ & $\begin{array}{l}\text { Se afecta al paisaje } \\
\text { de los cerros } \\
\text { orientales, debido } \\
\text { a que no son } \\
\text { estructuras } \\
\text { propiamente } \\
\text { naturales, algunas } \\
\text { de estas } \\
\text { estructuras de } \\
\text { edificios } \\
\text { monumentales se } \\
\text { pretenden levantar } \\
\text { humedales, lo cual } \\
\text { alteraría r las } \\
\text { dinámicas } \\
\text { naturales de estos } \\
\text { ecosistemas y } \\
\text { entorpecería su } \\
\text { función ambiental. }\end{array}$ & $\begin{array}{l}\text { Autores: } \\
\text { Taller } \\
\text { Jhody Sánchez } \\
\text { (estudiante de } \\
\text { física de la } \\
\text { universidad } \\
\text { pedagógica } \\
\begin{array}{ll}\text { Nacional) } & \\
& \\
\text { (grupo de } & 4 \\
\text { estudiantes } & \\
\text { ponentes) }\end{array}\end{array}$ & $\begin{array}{l}\text { - Yedizareth } \\
\text { Guerrero } \\
\text { Cuadros }\end{array}$ & 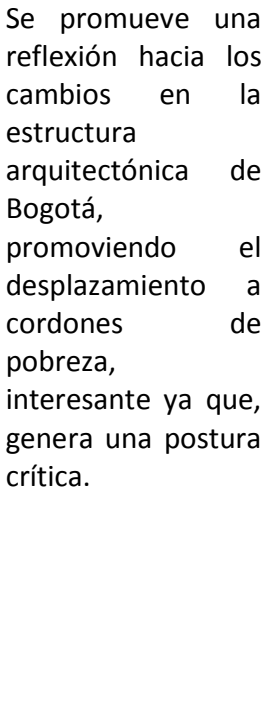 \\
\hline
\end{tabular}




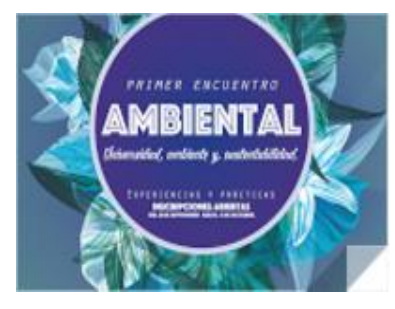

\section{UNIVERSIDAD PEDAGÓGICA NACIONAL}

\section{FACULTAD DE CIENCIA Y TECNOLOGÍA}

DEPARTAMENTO DE BIOLOGÍA

I ENCUENTRO AMBIENTAL FCT-UNIVERSIDAD, AMBIENTE Y SUSTENTABILIDAD

\section{SEMINARIO DE PROFUNDIZACION EN EDUCACION AMBIENTAL 2016.2}

\begin{tabular}{|c|c|c|c|c|c|c|c|}
\hline $\begin{array}{l}\text { Maquna de } \\
\text { Goldberg. } \\
\text { Tomada por: Guerrero Yedizareth } \\
\text { (2016). }\end{array}$ & $\begin{array}{lr}\text { Título: Prácticas } \\
\text { de laboratorio } \\
\text { sustentables: un } \\
\text { dialogo desde el } \\
\text { cuidado del } \\
\text { ambiente y la } \\
\text { enseñanza de la } \\
\text { física. Una } \\
\text { propuesta desde } \\
\text { la máquina de } \\
\text { Goldberg. }\end{array}$ & $\begin{array}{l}\text { Se realizaron cuatro } \\
\text { talleres } \\
\text { consecutivos, en } \\
\text { donde cada uno } \\
\text { consistía en aplicar } \\
\text { la máquina de } \\
\text { Goldberg desde la } \\
\text { cinemática, } \\
\text { electromagnetismo, } \\
\text { dinámica } \\
\text { termodinámica. } \\
\text { Utilizando } \\
\text { materiales } \\
\text { reciclables } \\
\text { produciendo una } \\
\text { energía limpia, } \\
\text { alternativa. }\end{array}$ & $\begin{array}{lr}\text { La máquina } & \text { se } \\
\text { vale de } & \text { las } \\
\text { reacciones } & \text { en } \\
\text { cadena } & \text { para } \\
\text { realizar } & \text { su } \\
\text { función. } & \end{array}$ & $\begin{array}{l}\text { Se promueve el } \\
\text { cuidado del } \\
\text { ambiente ya que } \\
\text { es una manera } \\
\text { simple y practica } \\
\text { para ejecutar una } \\
\text { acción sin alterar } \\
\text { mucho al } \\
\text { ambiente. }\end{array}$ & 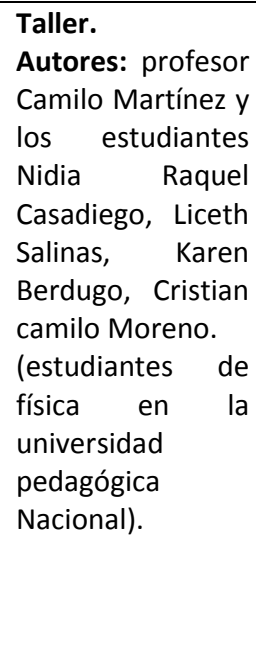 & $\begin{array}{l}\text { - Yedizareth } \\
\text { Guerrero } \\
\text { Cuadros }\end{array}$ & $\begin{array}{l}\text { Al ser talleres } \\
\text { interactivos, } \\
\text { posibilita que los } \\
\text { asistentes se } \\
\text { interesen más por } \\
\text { el tema. }\end{array}$ \\
\hline
\end{tabular}




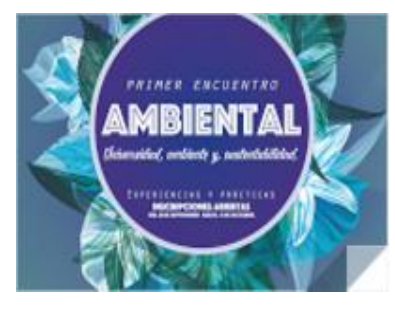

\section{UNIVERSIDAD PEDAGÓGICA NACIONAL}

\section{FACULTAD DE CIENCIA Y TECNOLOGÍA}

DEPARTAMENTO DE BIOLOGÍA

I ENCUENTRO AMBIENTAL FCT-UNIVERSIDAD, AMBIENTE Y SUSTENTABILIDAD

\section{SEMINARIO DE PROFUNDIZACION EN EDUCACION AMBIENTAL 2016.2}

\begin{tabular}{|c|c|c|c|c|c|c|c|}
\hline $\int_{11}$ & $\begin{array}{l}\text { Ciencia y } \\
\text { tecnología en } \\
\text { educación } \\
\text { ambiental. }\end{array}$ & $\begin{array}{l}\text { Charla en la que se } \\
\text { evidencia la } \\
\text { necesidad de } \\
\text { generar } \\
\text { tecnologías } \\
\text { amigables y un uso } \\
\text { responsable de las } \\
\text { tecnologías que ya } \\
\text { están. }\end{array}$ & $\begin{array}{l}\text { El compromiso del } \\
\text { docente para } \\
\text { formar un punto } \\
\text { de vista crítico en } \\
\text { los estudiantes, } \\
\text { sin delimitar su } \\
\text { conocimiento al } \\
\text { hombre. }\end{array}$ & $\begin{array}{l}\text { Es necesario } \\
\text { producir energías } \\
\text { limpias que no } \\
\text { afecten al planeta, } \\
\text { todas las que están } \\
\text { ahora afectan los } \\
\text { ecosistemas. }\end{array}$ & $\begin{array}{l}\text { Profesor de } \\
\text { Tecnología de la } \\
\text { UPN. } \\
\text { Autor: } \\
\text { Diego Acero }\end{array}$ & $\begin{array}{l}\text { - José Luis } \\
\text { Rincón }\end{array}$ & $\begin{array}{l}\text { El profesor muestra } \\
\text { la perspectiva } \\
\text { ambiental y su } \\
\text { inclusión en el } \\
\text { programa, desde los } \\
\text { saberes de las } \\
\text { tecnologías. }\end{array}$ \\
\hline Tomada por: Rincón Luis (2016). & & & & & & & \\
\hline
\end{tabular}

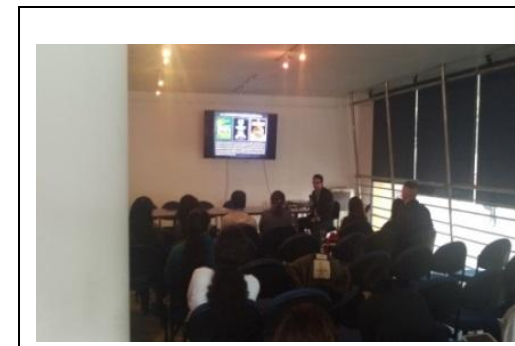

La formación de

Charla en la que se

El maestro en

profesores en

Ciencias hacia la

muestra un énfasis

sustentabilidad.

por parte de los

formación tiene

Los maestros tienen

obligación de

un papel clave en la

maestros en

generar un punto

consecución de la

Autor. Yair Porras

de vista crítico

sustentabilidad

trabajar la

con relación al

sustentabilidad.

discurso de la

educación

ambiental.

Tomada por: Rincón Luis (2016) 


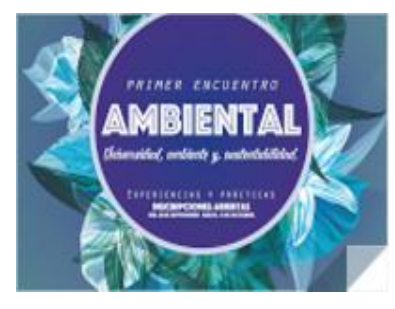

\section{UNIVERSIDAD PEDAGÓGICA NACIONAL \\ FACULTAD DE CIENCIA Y TECNOLOGÍA}

DEPARTAMENTO DE BIOLOGÍA

I ENCUENTRO AMBIENTAL FCT-UNIVERSIDAD, AMBIENTE Y SUSTENTABILIDAD

\section{SEMINARIO DE PROFUNDIZACION EN EDUCACION AMBIENTAL 2016.2}

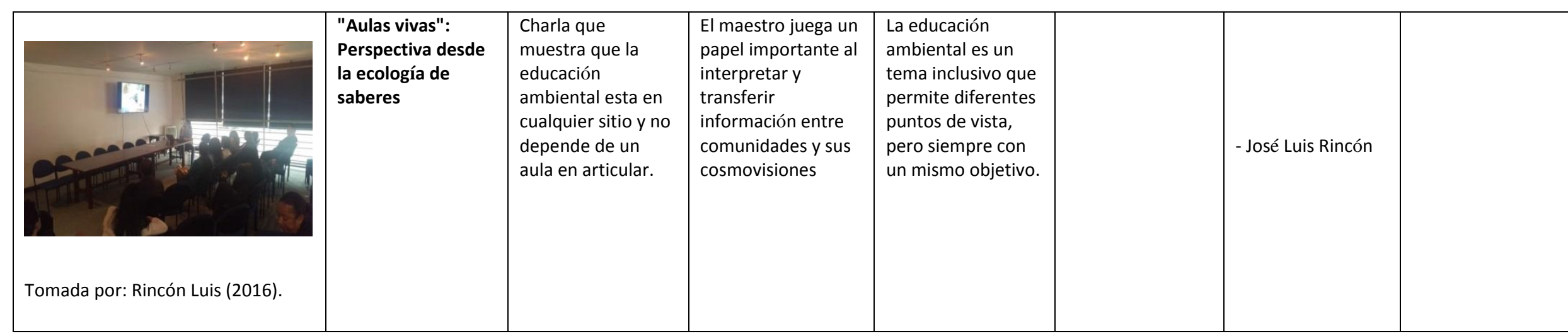

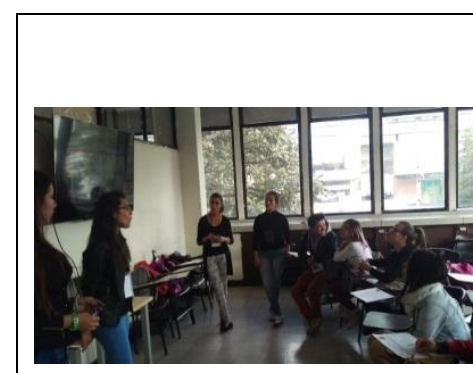

\begin{tabular}{l|l|l}
$\begin{array}{l}\text { Páramos de } \\
\text { Chingaza y } \\
\text { Sumapaz agua } \\
\text { para la vida }\end{array}$ & $\begin{array}{l}\text { Taller que muestra } \\
\text { una opción para la } \\
\text { conservación de los } \\
\text { páramos en } \\
\text { Colombia. }\end{array}$ & $\begin{array}{l}\text { El maestro como } \\
\text { posibilitador de } \\
\text { información para } \\
\text { generar nuevos } \\
\text { métodos de } \\
\text { conservación. }\end{array}$ \\
&
\end{tabular}

\begin{tabular}{|l|l|l|}
\hline $\begin{array}{l}\text { Como educar para } \\
\text { conservar desde } \\
\text { una visión holística. }\end{array}$ & & \\
& & \\
& & \\
& &
\end{tabular}




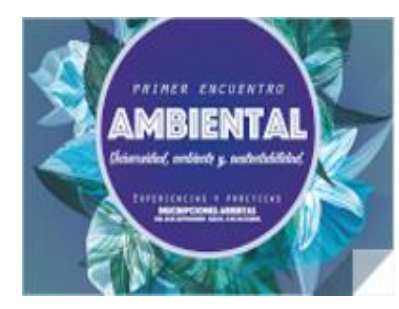

\section{UNIVERSIDAD PEDAGÓGICA NACIONAL}

\section{FACULTAD DE CIENCIA Y TECNOLOGÍA}

DEPARTAMENTO DE BIOLOGÍA

I ENCUENTRO AMBIENTAL FCT-UNIVERSIDAD, AMBIENTE Y SUSTENTABILIDAD

SEMINARIO DE PROFUNDIZACION EN EDUCACION AMBIENTAL 2016.2

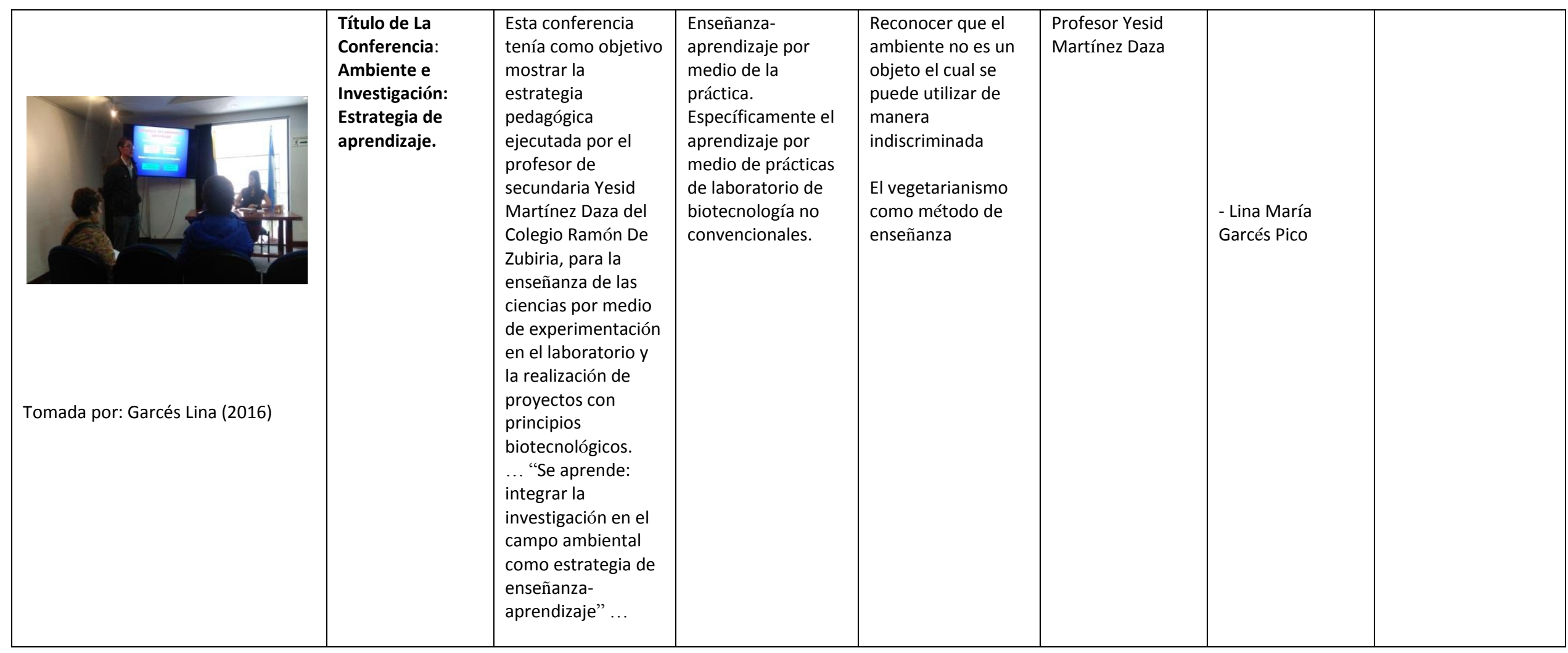




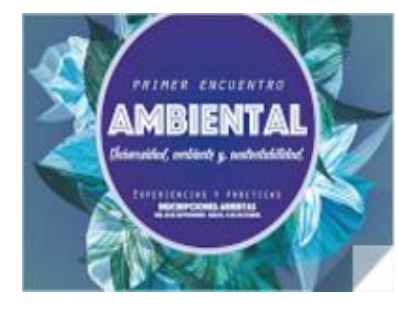

\section{UNIVERSIDAD PEDAGÓGICA NACIONAL \\ FACULTAD DE CIENCIA Y TECNOLOGÍA}

DEPARTAMENTO DE BIOLOGÍA

I ENCUENTRO AMBIENTAL FCT-UNIVERSIDAD, AMBIENTE Y SUSTENTABILIDAD

\section{SEMINARIO DE PROFUNDIZACION EN EDUCACION AMBIENTAL 2016.2}

\begin{tabular}{|c|c|c|c|c|c|c|c|}
\hline 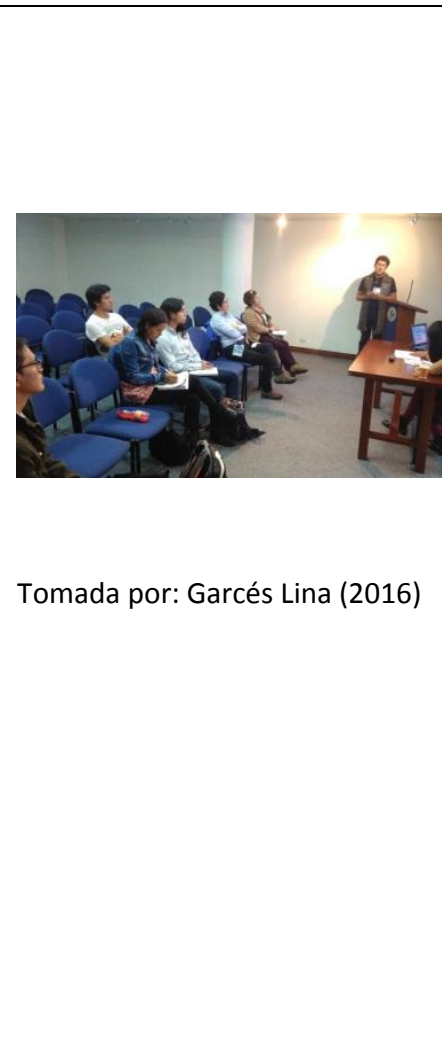 & $\begin{array}{l}\text { Trayectorias } \\
\text { investigativas del } \\
\text { grupo } \\
\text { Alternaciencias } \\
\text { para pensar la } \\
\text { dimensión } \\
\text { ambiental a } \\
\text { partir del } \\
\text { enfoque ciencia, } \\
\text { tecnología y } \\
\text { sociedad }\end{array}$ & 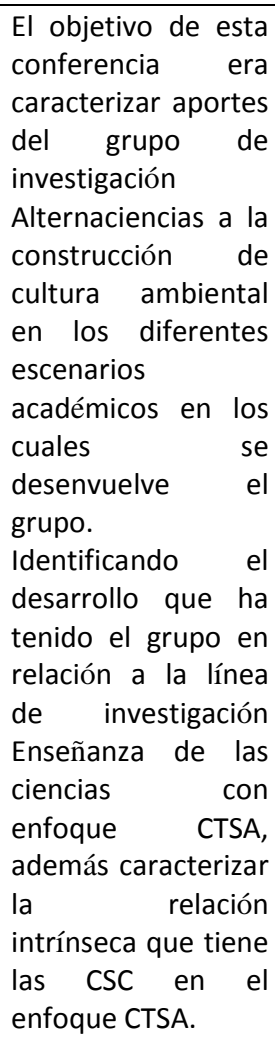 & $\begin{array}{l}\text { Grupo de } \\
\text { investigación en el } \\
\text { área ambiental } \\
\text { desde una mirada } \\
\text { Química }\end{array}$ & $\begin{array}{l}\text { Charla. } \\
\text { ¿Cómo la } \\
\text { investigación se } \\
\text { puede promover } \\
\text { desde temprana de } \\
\text { forma } \\
\text { interdisciplinar? }\end{array}$ & $\begin{array}{l}\text { Jhon Alexander } \\
\text { Gallo Ramírez, } \\
\text { Jhonny Alexander } \\
\text { Ortegón Moreno } \\
\text { y Leonardo Fabio } \\
\text { Martínez Pérez }\end{array}$ & 更 & $\begin{array}{l}\text { Cómo se formulan } \\
\text { preguntas } \\
\text { pertinentes y de } \\
\text { contexto, viables de } \\
\text { ser analizadas } \\
\text { críticamente }\end{array}$ \\
\hline
\end{tabular}




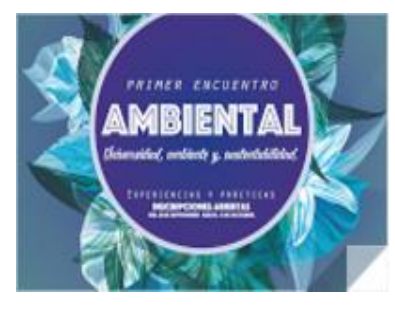

\section{UNIVERSIDAD PEDAGÓGICA NACIONAL}

\section{FACULTAD DE CIENCIA Y TECNOLOGÍA}

DEPARTAMENTO DE BIOLOGÍA

I ENCUENTRO AMBIENTAL FCT-UNIVERSIDAD, AMBIENTE Y SUSTENTABILIDAD

\section{SEMINARIO DE PROFUNDIZACION EN EDUCACION AMBIENTAL 2016.2}

\begin{tabular}{|c|c|c|c|c|c|c|c|}
\hline 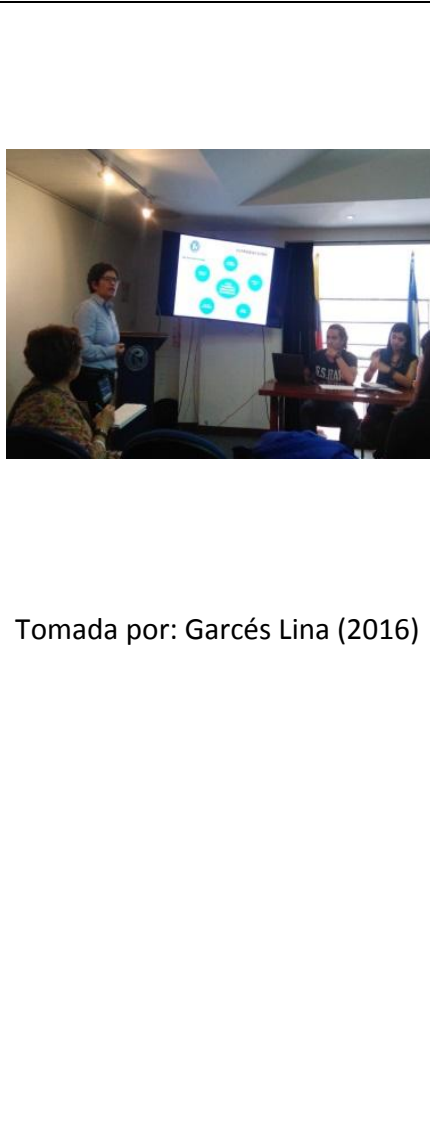 & $\begin{array}{l}\text { El voluntariado } \\
\text { de la Línea } \\
\text { Faunística y } \\
\text { conservación con } \\
\text { énfasis en los } \\
\text { artrópodos como } \\
\text { estrategia pata el } \\
\text { fomento de } \\
\text { actividades } \\
\text { educativas, } \\
\text { divulgativas e } \\
\text { investigativas } \\
\text { que promueven } \\
\text { la sustentabilidad. }\end{array}$ & $\begin{array}{l}\text { Esta conferencia } \\
\text { fue enfocada a } \\
\text { mostrar la } \\
\text { importancia del } \\
\text { voluntariado que se } \\
\text { realiza en la línea } \\
\text { de investigación, } \\
\text { que propone el } \\
\text { diseño, aplicación y } \\
\text { evaluación de } \\
\text { talleres en la } \\
\text { biología de la } \\
\text { conservación, } \\
\text { implementando } \\
\text { espacios } \\
\text { cotidianos de } \\
\text { enseñanza que } \\
\text { fomenten } \\
\text { educación ecológica } \\
\text { usando los insectos } \\
\text { como herramienta } \\
\text { de aprendizaje. } \\
\text { Además, } \\
\text { permitiendo que la } \\
\text { población de UPN } \\
\text { (Administrativos, } \\
\text { profesores, } \\
\text { estudiantes y } \\
\text { personal de } \\
\text { servicios generales) }\end{array}$ & $\begin{array}{lr}\text { La colaboración y } \\
\text { voluntariado visto } \\
\text { desde } \\
\text { perspectiva } \\
\text { innovadora donde } \\
\text { todos podemos } \\
\text { aprender } r \text { sin } \\
\text { importar si su } \\
\text { campo de acción es } \\
\text { la ciencia. }\end{array}$ & $\begin{array}{l}\text { Se realiza una } \\
\text { propuesta que } \\
\text { desde el } \\
\text { reconocimiento de } \\
\text { insectos se puede y } \\
\text { plantas se puede } \\
\text { realizar actividades } \\
\text { y proyectos de } \\
\text { investigación que } \\
\text { aporten al } \\
\text { aprendizaje de la } \\
\text { ecología de } \\
\text { ecosistema. }\end{array}$ & $\begin{array}{l}\text { Profesora de } \\
\text { Departamento de } \\
\text { Biología de la } \\
\text { Facultad de } \\
\text { Ciencia y } \\
\text { Tecnología, de la } \\
\text { UPN: } \\
\text { Autora: } \\
\text { Martha García }\end{array}$ & 更 & $\begin{array}{l}\text { Aporta en la } \\
\text { institucionalización } \\
\text { de un voluntariado } \\
\text { de estudiantes en } \\
\text { formación del } \\
\text { Departamento de } \\
\text { Biología, para la } \\
\text { conservación de las } \\
\text { colecciones del } \\
\text { Museo de la casita } \\
\text { de Biología. }\end{array}$ \\
\hline
\end{tabular}




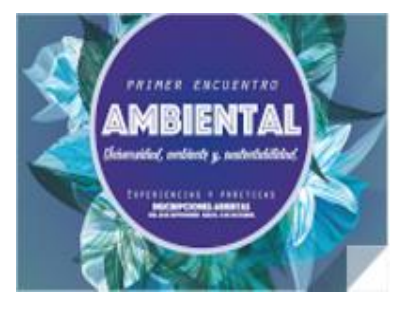

\section{UNIVERSIDAD PEDAGÓGICA NACIONAL}

\section{FACULTAD DE CIENCIA Y TECNOLOGÍA}

DEPARTAMENTO DE BIOLOGÍA

I ENCUENTRO AMBIENTAL FCT-UNIVERSIDAD, AMBIENTE Y SUSTENTABILIDAD

\section{SEMINARIO DE PROFUNDIZACION EN EDUCACION AMBIENTAL 2016.2}

\begin{tabular}{|c|c|c|c|c|c|c|c|}
\hline & & $\begin{array}{l}\text { se acerque a } \\
\text { conocer estos } \\
\text { animales y pierdan } \\
\text { el miedo o asco pro } \\
\text { ellos y puedan } \\
\text { reconocer la } \\
\text { importancia que } \\
\text { tiene para el } \\
\text { ecosistema. }\end{array}$ & & & & & \\
\hline Tomada por: Garcés Lina (2016) & $\begin{array}{l}\text { La cara oculta del } \\
\text { activismo } \\
\text { ambiental en la } \\
\text { UPN: cronología } \\
\text { de experiencias }\end{array}$ & $\begin{array}{l}\text { La charla se enfocó } \\
\text { en mostrar los } \\
\text { diferentes } \\
\text { proyectos } \\
\text { realizados por la } \\
\text { UPN, desde hace } \\
\text { más de } 15 \text { años } \\
\text { para el re } \\
\text { significación y el } \\
\text { conocimiento de } \\
\text { espacios naturales } \\
\text { en la región y de } \\
\text { Colombia, a través } \\
\text { del activismo } \\
\text { ecológico. }\end{array}$ & $\begin{array}{lr}\text { Se realiza un } & \text { un } \\
\text { proceso de } & \text { de } \\
\text { enseñanza desde } \\
\text { escenarios no } \\
\text { convencionales, } \\
\text { donde se incluye a } \\
\text { toda la comunidad } \\
\text { universitaria } \\
\text { (directivos, } \\
\text { profesores, } \\
\text { estudiantes, de } \\
\text { personal } \\
\text { servicios generales), }\end{array}$ & $\begin{array}{l}\text { Se realizan } \\
\text { recorridos y salidas } \\
\text { con el propósito de } \\
\text { motivar a la } \\
\text { comunidad } \\
\text { universitaria UPN y } \\
\text { así lograr un re } \\
\text { significación } \\
\text { ambiental } \\
\text { reconocer y } \\
\text { territorios los } \\
\text { ambientales locales } \\
\text { y regionales a } \\
\text { través de una } \\
\text { galería fotográfica. }\end{array}$ & $\begin{array}{l}\text { Charla y Galería } \\
\text { fotográfica } \\
\text { virtual. } \\
\text { Funcionario de la } \\
\text { UPN. } \\
\text { Carlos Julio Galvis }\end{array}$ & 更 & $\begin{array}{l}\text { Interesante la } \\
\text { muestra de } \\
\text { fotografías de } \\
\text { excelente calidad, a } \\
\text { través de una Galería } \\
\text { de imágenes } \\
\text { logradas y archivadas } \\
\text { por más de } 15 \text { años } \\
\text { de los recorridos } \\
\text { ambientales en la } \\
\text { UPN. }\end{array}$ \\
\hline & $\begin{array}{l}\text { Estación de } \\
\text { medición de } \\
\text { radiación solar } \\
\text { bioinspirada en la }\end{array}$ & $\begin{array}{l}\text { La conferencia se } \\
\text { centró en mostrar } \\
\text { el trabajo de grado } \\
\text { del egresado Julián }\end{array}$ & $\begin{array}{l}\text { La combinación de } \\
\text { la biología con la } \\
\text { tecnología para la } \\
\text { realización de una }\end{array}$ & $\begin{array}{l}\text { La mimosa púdica } \\
\text { planta herbácea } \\
\text { tropical, con } \\
\text { movimientos }\end{array}$ & $\begin{array}{l}\text { Charla } \\
\text { Autor: } \\
\text { Julián David } \\
\text { Aguilar Mayorga. }\end{array}$ & & $\begin{array}{l}\text { Interesante la } \\
\text { propuesta, con una } \\
\text { concepción } \\
\text { altamente inspirada }\end{array}$ \\
\hline
\end{tabular}




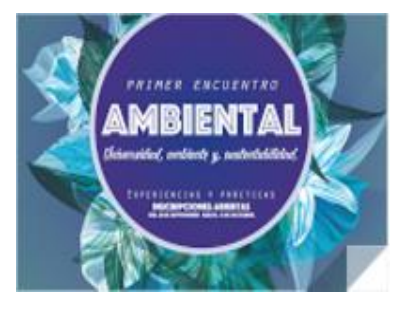

\section{UNIVERSIDAD PEDAGÓGICA NACIONAL}

\section{FACULTAD DE CIENCIA Y TECNOLOGÍA}

DEPARTAMENTO DE BIOLOGÍA

I ENCUENTRO AMBIENTAL FCT-UNIVERSIDAD, AMBIENTE Y SUSTENTABILIDAD

\section{SEMINARIO DE PROFUNDIZACION EN EDUCACION AMBIENTAL 2016.2}

\begin{tabular}{|c|c|c|c|c|c|c|}
\hline Tomada por: Garcés Lina (2016) & mimosa púdica. & 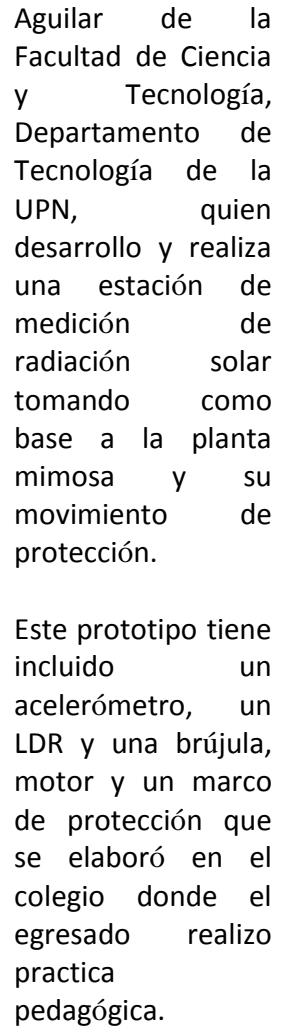 & $\begin{array}{l}\text { estación de } \\
\text { medición de } \\
\text { radiación, } \\
\text { implementando } \\
\text { saberes de las dos } \\
\text { áreas para innovar } \\
\text { en la formulación } \\
\text { de tecnología en } \\
\text { pro del ambiente. }\end{array}$ & $\begin{array}{l}\text { nictinasticos y } \\
\text { Seismoniasticos, } \\
\text { Ornamental, que } \\
\text { reaccionan al tacto } \\
\text { humano. } \\
\text { Muestra el } \\
\text { prototipo realizado } \\
\text { con tecnología y un } \\
\text { costo asequible. }\end{array}$ & $\begin{array}{l}\text { - Lina María } \\
\text { Garcés Pico }\end{array}$ & $\begin{array}{l}\text { en los } \\
\text { comportamientos de } \\
\text { la biota de Colombia. } \\
\text { Dejando ver la } \\
\text { transdisciplinariedad } \\
\text { de asuntos } \\
\text { tecnológicos y } \\
\text { biológicos. }\end{array}$ \\
\hline
\end{tabular}




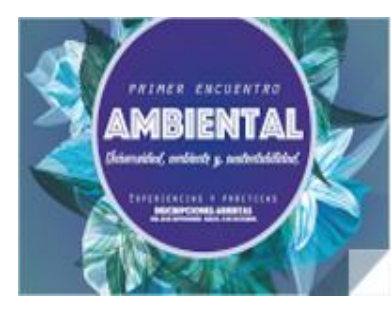

\section{UNIVERSIDAD PEDAGÓGICA NACIONAL}

\section{FACULTAD DE CIENCIA Y TECNOLOGÍA}

DEPARTAMENTO DE BIOLOGÍA

I ENCUENTRO AMBIENTAL FCT-UNIVERSIDAD, AMBIENTE Y SUSTENTABILIDAD

\section{SEMINARIO DE PROFUNDIZACION EN EDUCACION AMBIENTAL 2016.2}

\begin{tabular}{|c|c|c|c|c|c|c|c|}
\hline$\sum_{-\infty}^{1+1}$ & $\begin{array}{l}\text { La educación } \\
\text { ambiental en el } \\
\text { IED Campestre } \\
\text { Monteverde a } \\
\text { través de las } \\
\text { prácticas } \\
\text { docentes }\end{array}$ & $\begin{array}{l}\text { La charla quiere } \\
\text { mostrar un ejemplo } \\
\text { claro de lo que los } \\
\text { Docentes pueden } \\
\text { hacer para mejorar } \\
\text { la educación } \\
\text { ambiental en los } \\
\text { colegios donde } \\
\text { trabajan, como } \\
\text { realizar trabajos de } \\
\text { gestión de residuos } \\
\text { donde lo principal } \\
\text { no sea el reciclaje } \\
\text { de papel, sino el } \\
\text { manejo de los } \\
\text { residuos orgánicos } \\
\text { que se producen } \\
\text { del refrigerio } \\
\text { escolar a través de } \\
\text { la organización de } \\
\text { un compostero. } \\
\text { Proponer } \\
\text { actividades para } \\
\text { fortalecer prácticas } \\
\text { de integración } \\
\text { disciplinar y } \\
\text { trabajos con } \\
\text { constancia y } \\
\text { herramientas de } \\
\text { trabajo }\end{array}$ & $\begin{array}{l}\text { La educación } \\
\text { ambiental como } \\
\text { metodología de } \\
\text { enseñanza para la } \\
\text { incorporación de } \\
\text { diferentes áreas en } \\
\text { proyectos escolares } \\
\text { que motiven a los } \\
\text { estudiantes por el } \\
\text { aprendizaje de las } \\
\text { ciencias }\end{array}$ & $\begin{array}{l}\text { Contribuciones a los } \\
\text { convenios } \\
\text { interinstitucionales } \\
\text { de propuestas de } \\
\text { estudiantes } \\
\text { practicantes en } \\
\text { formación y } \\
\text { trabajos de grado, } \\
\text { de la UPN para } \\
\text { fortalecer y } \\
\text { promover la } \\
\text { educación } \\
\text { ambiental, en las } \\
\text { Instituciones } \\
\text { Educativas } \\
\text { Oficiales. }\end{array}$ & $\begin{array}{l}\text { Charla. } \\
\text { Autora } \\
\text { Profesora UPN- } \\
\text { Departamento de } \\
\text { Biología. } \\
\text { Paola Jiménez }\end{array}$ & $\begin{array}{l}\text { - Lina María } \\
\text { Garcés } \\
\text { Pico }\end{array}$ & $\begin{array}{l}\text { Las acciones de } \\
\text { gestión ambiental de } \\
\text { los profesores de la } \\
\text { UPN, para lograr } \\
\text { convenios } \\
\text { interinstitucionales } \\
\text { con Instituciones } \\
\text { Educativas oficiales. }\end{array}$ \\
\hline
\end{tabular}




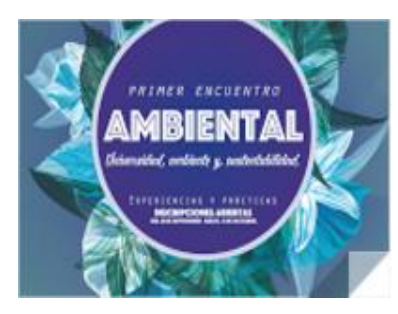

\section{UNIVERSIDAD PEDAGÓGICA NACIONAL}

\section{FACULTAD DE CIENCIA Y TECNOLOGÍA}

DEPARTAMENTO DE BIOLOGÍA

I ENCUENTRO AMBIENTAL FCT-UNIVERSIDAD, AMBIENTE Y SUSTENTABILIDAD

\section{SEMINARIO DE PROFUNDIZACION EN EDUCACION AMBIENTAL 2016.2}

\begin{tabular}{|c|c|c|c|c|c|c|c|}
\hline Tomada por: Garcés Lina (2016) & $\begin{array}{l}\text { Psicología } \\
\text { positiva de la } \\
\text { sustentabilidad } \\
\text { ambiental. Un } \\
\text { modelo para la } \\
\text { educación } \\
\text { ambiental }\end{array}$ & $\begin{array}{l}\text { La conferencia } \\
\text { explica la psicología } \\
\text { positiva de la } \\
\text { sustentabilidad la } \\
\text { cual es un modelo } \\
\text { para la educación } \\
\text { ambiental que } \\
\text { contiene y } \\
\text { categorías } \\
\text { virtudes que son un } \\
\text { concepto abstracto. } \\
\text { Las personas actúan } \\
\text { de una forma } \\
\text { sustentable si se } \\
\text { incentiva las } \\
\text { fortalezas y no el } \\
\text { problema, tener } \\
\text { una motivación } \\
\text { positiva, } \\
\text { comprendiendo } \\
\text { que no se debe ser } \\
\text { una obligación, por } \\
\text { el contrario, la } \\
\text { motivación debe } \\
\text { provenir de algo } \\
\text { positivo para que el } \\
\text { sujeto quiera hacer } \\
\text { actividades por el } \\
\text { bienestar del medio } \\
\text { ambiente. }\end{array}$ & $\begin{array}{l}\text { Una mirada de la } \\
\text { psicología para la } \\
\text { enseñanza de la } \\
\text { educación } \\
\text { ambiental desde } \\
\text { una perspectiva } \\
\text { sustentable, } \\
\text { cambiando a } \\
\text { nuevos paradigmas } \\
\text { y metodologías. }\end{array}$ & 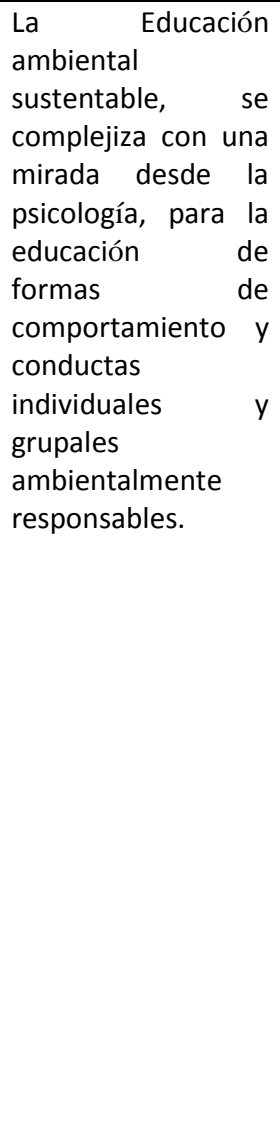 & $\begin{array}{l}\text { Charla. } \\
\text { Autor: } \\
\text { Profesor de la } \\
\text { UPN: Carlos } \\
\text { Botero Arias }\end{array}$ & 更 & $\begin{array}{l}\text { Abrir el abanico de } \\
\text { posibilidades para } \\
\text { una educación } \\
\text { ambiental } \\
\text { sustentable, } \\
\text { responsable desde } \\
\text { un análisis crítico y } \\
\text { desde la Psicología. }\end{array}$ \\
\hline
\end{tabular}




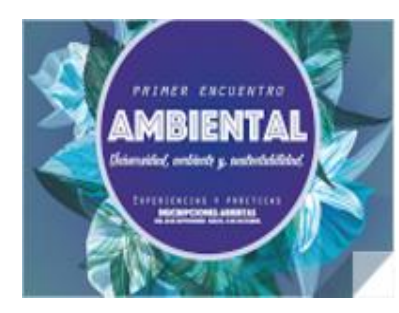

\section{UNIVERSIDAD PEDAGÓGICA NACIONAL}

\section{FACULTAD DE CIENCIA Y TECNOLOGÍA}

DEPARTAMENTO DE BIOLOGÍA

I ENCUENTRO AMBIENTAL FCT-UNIVERSIDAD, AMBIENTE Y SUSTENTABILIDAD

\section{SEMINARIO DE PROFUNDIZACION EN EDUCACION AMBIENTAL 2016.2}

\begin{tabular}{|c|c|c|c|c|c|c|c|}
\hline Tomada por: Garcés Lina (2016) & $\begin{array}{lr}\text { Taller. Educación } \\
\text { ambiental: las } \\
\text { practicas } & \\
\text { sustentables } & \\
\text { desde } & \text { lo } \\
\text { cotidiano } & \end{array}$ & 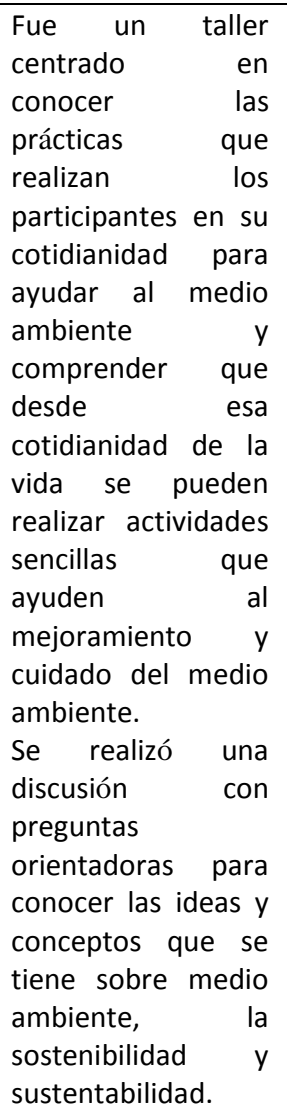 & $\begin{array}{l}\text { Mostrar la idea del } \\
\text { grupo de } \\
\text { investigación y } \\
\text { promover la } \\
\text { discusión en torno a } \\
\text { la educación } \\
\text { ambiental y de } \\
\text { cómo cada persona } \\
\text { puede contribuirle } \\
\text { al ambiente desde } \\
\text { su cotidianidad }\end{array}$ & 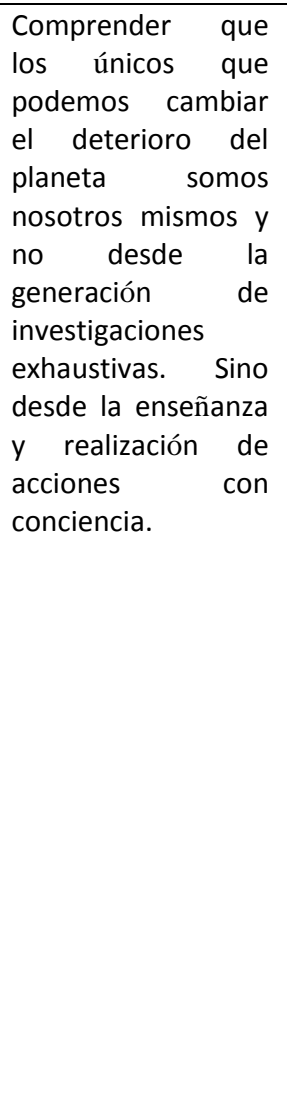 & $\begin{array}{l}\text { Taller. } \\
\text { Autores (as): } \\
\text { Angélica M. De } \\
\text { Felipe Ortiz, } \\
\text { Natalia Martínez } \\
\text { Morales } \\
\text { Jeisson Ávila }\end{array}$ & 更 & $\begin{array}{l}\text { El cuidado del Medio } \\
\text { ambiente desde } \\
\text { prácticas de } \\
\text { enseñanza sencillas, } \\
\text { una posibilidad de } \\
\text { Educación ambiental. }\end{array}$ \\
\hline
\end{tabular}




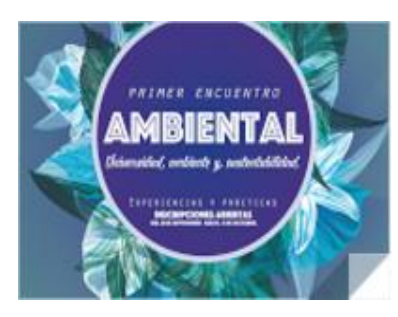

\section{UNIVERSIDAD PEDAGÓGICA NACIONAL}

\section{FACULTAD DE CIENCIA Y TECNOLOGÍA}

DEPARTAMENTO DE BIOLOGÍA

I ENCUENTRO AMBIENTAL FCT-UNIVERSIDAD, AMBIENTE Y SUSTENTABILIDAD

\section{SEMINARIO DE PROFUNDIZACION EN EDUCACION AMBIENTAL 2016.2}

\begin{tabular}{|c|c|c|c|c|c|c|c|}
\hline & & $\begin{array}{l}\text { Por último, se } \\
\text { realizó un test } \\
\text { individual y la } \\
\text { decoración } \\
\text { frascos de vidrio. }\end{array}$ & & & & & \\
\hline $\begin{array}{l}\text { Tomada por: Guerrero Yedizareth } \\
\text { (2016). }\end{array}$ & $\begin{array}{l}\text { Clausura del } \\
\text { evento }\end{array}$ & $\begin{array}{l}\text { Se finalizó el } \\
\text { encuentro } \\
\text { ambiental con una } \\
\text { muestra cultural del } \\
\text { grupo de música } \\
\text { Tamboras son del } \\
\text { Mar de la } \\
\text { Universidad } \\
\text { Pedagógica } \\
\text { Nacional }\end{array}$ & $\begin{array}{lr}\text { Palabras finales } & \text { recogidas por la } \\
\text { profesora Adriana } \\
\text { Tovar en donde se } \\
\text { ratifica ra la } \\
\text { importancia del } \\
\text { encuentro a nivel } \\
\text { de mostrar un } \\
\text { abanico } & \text { de } \\
\text { posibilidades de } \\
\text { educación } \\
\text { ambiental } \\
\text { sustentable, y la } \\
\text { interdisciplinarieda } \\
\text { d con lo curricular, } \\
\text { didáctico y } \\
\text { Pedagógico. }\end{array}$ & $\begin{array}{l}\text { En el cierre se } \\
\text { expresan aspectos } \\
\text { de integración entre } \\
\text { los diferentes } \\
\text { participantes } \\
\text { estudiantes y } \\
\text { profesores, del } \\
\text { Encuentro } \\
\text { ambiental } \\
\text { Universidad, } \\
\text { ambiente } \\
\text { Sustentabilidad, a } \\
\text { través de la muestra } \\
\text { musical de } \\
\text { tamboras y gaitas. }\end{array}$ & $\begin{array}{l}\text { Encuentro } \\
\text { musical donde se } \\
\text { aprecian } \\
\text { manifestaciones } \\
\text { de integración a } \\
\text { través de la } \\
\text { muestra cultural. }\end{array}$ & $\begin{array}{l}\text { - Yedizareth } \\
\text { Guerrero Cuadros }\end{array}$ & $\begin{array}{l}\text { Se termina el } \\
\text { encuentro ambiental } \\
\text { de la Facultad de } \\
\text { Ciencia y Tecnología } \\
\text { a las 6:30 p.m. con } \\
\text { una muestra cultural. }\end{array}$ \\
\hline
\end{tabular}

